\title{
Evaluation of cloud convection and tracer transport in a three-dimensional chemical transport model
}

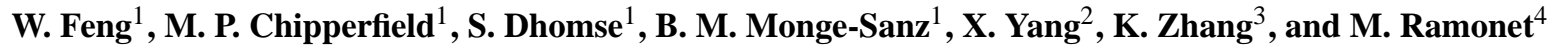 \\ ${ }^{1}$ NCAS, Institute for Climate and Atmospheric Science, School of Earth and Environment, University of Leeds, Leeds, UK \\ ${ }^{2}$ NCAS, Department of Chemistry, University of Cambridge, Cambridge, UK \\ ${ }^{3}$ Max-Planck-Institut für Meteorologie, Hamburg, Germany \\ ${ }^{4}$ LSCE/IPSL, CEA-CNRS-UVSQ, France
}

Received: 2 September 2010 - Published in Atmos. Chem. Phys. Discuss.: 6 October 2010

Revised: 15 June 2011 - Accepted: 17 June 2011 - Published: 22 June 2011

\begin{abstract}
We investigate the performance of cloud convection and tracer transport in a global off-line 3-D chemical transport model. Various model simulations are performed using different meteorological (re)analyses (ERA40, ECMWF operational and ECMWF Interim) to diagnose the updraft mass flux, convective precipitation and cloud top height.

The diagnosed upward mass flux distribution from TOMCAT agrees quite well with the ECMWF reanalysis data (ERA-40 and ERA-Interim) below $200 \mathrm{hPa}$. Inclusion of midlevel convection improves the agreement at mid-high latitudes. However, the reanalyses show strong convective transport up to $100 \mathrm{hPa}$, well into the tropical tropopause layer (TTL), which is not captured by TOMCAT. Similarly, the model captures the spatial and seasonal variation of convective cloud top height although the mean modelled value is about $2 \mathrm{~km}$ lower than observed.

The ERA-Interim reanalyses have smaller archived upward convective mass fluxes than ERA-40, and smaller convective precipitation, which is in better agreement with satellite-based data. TOMCAT captures these relative differences when diagnosing convection from the large-scale fields. The model also shows differences in diagnosed convection with the version of the operational analyses used, which cautions against using results of the model from one specific time period as a general evaluation.

We have tested the effect of resolution on the diagnosed modelled convection with simulations ranging from $5.6^{\circ} \times 5.6^{\circ}$ to $1^{\circ} \times 1^{\circ}$. Overall, in the off-line model, the higher model resolution gives stronger vertical tracer transport, however, it does not make a large change to the diag-
\end{abstract}

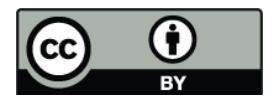

Correspondence to: M. P. Chipperfield (m.chipperfield@leeds.ac.uk) nosed convective updraft mass flux (i.e., the model results using the convection scheme fail to capture the strong convection transport up to $100 \mathrm{hPa}$ as seen in the archived convective mass fluxes). Similarly, the resolution of the forcing winds in the higher resolution CTM does not make a large improvement compared to the archived mass fluxes.

Including a radon tracer in the model confirms the importance of convection for reproducing observed midlatitude profiles. The model run using archived mass fluxes transports significantly more radon to the upper troposphere but the available data does not strongly discriminate between the different model versions.

\section{Introduction}

Cumulus cloud convection is one of the major processes that affects the dynamics and energetics of atmospheric circulation systems (Bechtold et al., 2001). Convection has to be parameterised in all general circulation models (GCMs) and most numerical weather prediction (NWP) models due to their coarse spatial resolution. The cumulus parameterisation aims to represent/formulate the collective effects of subgrid-scale clouds on mass, momentum, vorticity and tracer distribution in terms of grid-scale prognostic variables in numerical models (e.g., Arakawa, 1993).

There are two types of cumulus parameterisations used in large-scale models: (1) Convective adjustment schemes (e.g. Manabe et al., 1965) are used to simulate the effects of dry and/or moist convection by adjusting the lapse rates of temperature and moisture to specified profiles within the local grid column which oversimplifies the physical process (Emanuel, 1994). (2) Mass-flux schemes use a cloud model to explicitly calculate profiles of cumulus mass flux and thermodynamic variables (e.g., Tiedtke, 1989). Mass

Published by Copernicus Publications on behalf of the European Geosciences Union. 
flux schemes have been more widely used in models because they can provide an internally consistent representation of turbulent mixing, updraft dynamics, microphysics and tracer transport.

Off-line three-dimensional chemical transport models (CTMs) are widely used to study processes controlling tracer distributions in the atmosphere. Although most CTMs can reproduce the general features of tracer distributions, there are still large uncertainties in the model simulations. This is due to the complex set of processes in the model (e.g., chemistry, photolysis, aerosol, large-scale advection, convection, dry/wet deposition, planetary boundary layer mixing, emissions) as well as the quality of meteorological analysis data used. The parameterisation of sub-gridscale transport processes in CTMs is particularly problematic. The two possible approaches are (i) include a scheme in the CTM to diagnose convection from the large-scale meteorological fields or (ii) read in information on convective transport (i.e. from the same source which provides large-scale winds). Approach (i) is necessary if only the large-scale meteorological fields are available. For example, the ECMWF does not routinely archive information on convection in their operational analyses, although they do for the lower resolution reanalyses such as ERA-40 and ERA-Interim. However, in approach (i) the CTM is attempting to diagnose convection from large-scale fields which may have already experienced its effects, i.e. they are already stabilised. Approach (ii) has the advantage that the CTM transport will be more fully consistent with the dynamics of the NWP model (or GCM) providing the meteorological data. However, this approach still depends on the accuracy of the convection produced in the NWP system.

Mahowald et al. (1995) compared the performance of 7 different convection parameterisations within the same CTM. The schemes tested included two versions of the Tiedtke (1989) scheme. They found that tracer distributions in the CTM were very sensitive to the choice of convection scheme. They emphasised that their tests were not able to definitively determine if any scheme was better than the others though they found that the Tiedtke scheme generally performed well. Tost et al. (2006) tested a range of convection parameterisations within the framework of a general circulation model (GCM). As they were dealing with a GCM the focus was on investigating differences in the hydrological cycle and meteorology. In a later paper Tost et al. (2007) compared convection/lightning parameterisations within the same model. Recently, Tost et al. (2010) extended their studies by investigating tracer transport. By comparing with campaign data they found the shorter the lifetime of a species, the larger the impact of different convection schemes. While longer lived species such as $\mathrm{CO}$ and $\mathrm{O}_{3}$ varied by $\pm 25 \%$ with different schemes, shorter lived species varied by $\pm 100 \%$.

Examples of off-line tropospheric CTMs which use archived convective mass fluxes include the Oslo CTM2 (Berntsen et al., 2006) and the related FRGSUCI model (Wild et al., 2004). These avoid the problem of availability of convection information by producing their own forecast data by running a version of the ECMWF Integrated Forecast System (IFS) model. As a variation on this approach, Aschmann et al. (2009) used archived ECMWF ERA-Interim convective detrainment rates to model tracer transport in the upper troposphere. Their off-line model had a lower boundary at $330 \mathrm{~K}$ (about $10 \mathrm{~km}$ ) and they used the archived detrainment rates in the upper troposphere (UT), along with an assumed tracer mixing ratio in the convective plume, to inject tracers into the lower model levels. This approach allowed them to reproduce observed profiles of $\mathrm{CHBr}_{3}$ and $\mathrm{CH}_{3} \mathrm{I}$ in the tropical UT.

As part of the EU SCOUT-O3 project, Russo et al. (2011) and Hoyle et al. (2010) compared the treatment of convection in global GCMs, global CTMs (including our default TOMCAT model) and regional mesoscale models. Russo et al. (2011) focused on the meteorology while Hoyle et al. (2010) compared the transport of short-lived species to and through the tropical tropopause layer (TTL). Their idealised model tracers had lifetimes ranging from $6 \mathrm{~h}$ to 20 days. The different models produced very different rates of transport of short-lived species to the TTL and there were also significant differences between the 5 CTMs considered, despite the fact they were all forced by ECMWF meteorology. Clearly the details of the models' convection treatments are likely to play a key role in determining these different distributions of short-lived tracers in the TTL, however other model differences (e.g. resolution, advection scheme) may also play a role.

Therefore, a key uncertainty in tropospheric CTMs is the accuracy of modelled sub-gridscale transport by convection. In this paper we investigate the performance of cloud convection and tropospheric tracer transport in the TOMCAT 3-D CTM (Chipperfield et al., 1993; Chipperfield, 2006). We compare approaches which diagnose convection from the large-scale meteorological fields with using mass fluxes archived by NWP systems. Therefore, we are able to investigate specific causes for the different performance of CTMs reported in Hoyle et al. (2010). For the diagnosed convection we investigate the impact of resolution on the modelled convection, the impact of different external forcing meteorology and surface data, and the use of different parameterisations. We evaluate the model by comparing diagnosed convective quantities with ECMWF reanalyses and observations, and by using radon as a model tracer.

Section 2 of this paper describes the TOMCAT CTM and modifications made for this study. Section 3 describes the meteorological data used to force the model and the observations used to test the convection parameterisation. The model results are presented in Sect. 4 and further discussed in Sect. 5. Our conclusions are presented in Sect. 6. 


\section{Model and experiments}

\subsection{TOMCAT 3-D CTM}

TOMCAT/SLIMCAT is an off-line 3-D CTM first described in Chipperfield et al. (1993). The TOMCAT version uses a hybrid $\sigma-p$ vertical coordinate and the model has a variable horizontal resolution and vertical levels. Tracers are transported by resolved, large-scale advection, convection and parameterised mixing in the boundary layer. Horizontal winds, temperatures and specific humidity are specified using ECMWF meteorological (re)analyses (ECMWF operational analyses, ERA-40 or ERA-Interim analyses). Vertical advection is diagnosed from the large-scale divergence field (Chipperfield, 1999, 2006). The model uses the Prather (1986) advection scheme which conserves secondorder moments of transport tracers and uses vertical turbulent parameterisation of Holtslag and Boville (1993) for the boundary layer mixing. Versions of the model which contain detailed chemical and aerosol schemes (e.g. Breider et al., 2010) are based on the same dynamical framework.

The convection scheme in TOMCAT is based on Tiedtke (1989) which uses a bulk entraining plume-type cloud model for all convective types and assumes different entrainment and detrainment rates for different types of convection. In general the Tiedtke scheme considers three types of convection (deep, shallow, midlevel) and includes an unsaturated downdraft. Deep convection is driven by moisture convergence in the entire column. Shallow convection is driven by moisture convergence in the boundary layer, and the midlevel convection occurs when there is upward motion creating conditional instability (e.g., Tiedtke, 1989; Mahowald et al., 1997). The default TOMCAT convection scheme includes cumulus updrafts in the vertical column, entrainment of environmental air into the cloud and detrainment of cloud air to the environment (similar to the "TiedtkeTM2" code tested by Mahowald et al., 1995). However, it does not include midlevel convection and convective downdrafts and there is no organised entrainment of environmental air above cloud base (see Stockwell and Chipperfield, 1999; hereafter SC1999).

Recently we have extended the options of moist convection parameterisations in TOMCAT. We have updated the default convection scheme to include midlevel convection and convective downdrafts. The entrainment and detrainment rates for the three types of convection use the same values as Tiedtke (1989). Vertical wind speed is diagnosed from the (re)analysis divergence fields. Large-scale ascent and an environmental relative humidity of more than $90 \%$ are needed for midlevel convection to occur which is the same as in the CHIMERE CTM (Hodzic et al., 2006). The magnitudes of the entrainment/detrainment are related to horizontal convergence of moisture below cloud and the difference between cloud and environmental specific humidity at cloud base. Mass balance within the vertical column is maintained by including sub-grid subsidence of environmental air (induced by convection) within the same timestep.

In the Tiedtke scheme, the updraft mass flux is proportional to boundary layer moisture convergence for the shallow and deep convection and the upward motion in the midlevel convection while the height of convection is dependent on the buoyancy of the plume. Therefore, the surface evaporation flux is an essential input for the model moisture convergence. The default TOMCAT uses evaporation fluxes from the UGAMP GCM (see SC1999) which are available at a resolution of $2.8^{\circ} \times 2.8^{\circ}$. For this work we created a high resolution evaporation flux dataset at $1^{\circ} \times 1^{\circ}$ resolution, from an interpolation of the UGAMP GCM data, to enable the model to run at higher horizontal resolution. When used in the model this $1^{\circ} \times 1^{\circ}$ dataset is area-weighted averaged onto the lower resolution grid.

As an alternative to the Tiedtke scheme, we have updated TOMCAT to include the option of using mass fluxes of entrainment and detrainment in the updrafts and downdrafts archived from NWP simulations in the CTM. To be consistent with the large-scale TOMCAT forcing, here we use the ERA-Interim archived mass fluxes. We retrieved the updraft/downdraft detrainment rate and updraft/downdraft mass flux at $1^{\circ} \times 1^{\circ}$ L60 resolution from the ECMWF Meteorological Archival and Retrieval System (MARS) and recalculated the instantaneous updraft/downdraft entrainment/detrainment mass flux every six hours, to match the availability of the other meteorological forcing data. These fluxes are then used in the model's convective transport scheme instead of the fluxes diagnosed from the Tiedtke scheme.

For a comparison of convective precipitation (CP) the model includes a simple treatment to calculate this, based on SC1999. The CP in TOMCAT occurs above a cloud depth of $1500 \mathrm{~m}$. The rainfall rate in each model level above the $1.5 \mathrm{~km}$ is calculated based on the following equation:

$\mathrm{CP}=C \times \mathrm{LWC} \times \varrho \times d z$

if there is sufficient updraft mass flux to maintain this, otherwise it is calculated as:

$\mathrm{CP}=\mathrm{LWC} \times \mu$

Here $C$ is the constant for precipitation parameterization which uses the same value $\left(2.0 \times 10^{-3} \mathrm{~s}^{-1}\right)$ as Tiedkte (1989). LWC is the liquid water content, $\varrho$ is the environmental air density, $\mathrm{dz}$ is the vertical depth of the model level while $\mu$ is the convective updraft mass flux.

\subsection{Experiments}

A series of 16 model runs were conducted to investigate the performance of the convection scheme in the TOMCAT model (see Table 1). The basic model was run at a horizontal resolution of $2.8^{\circ} \times 2.8^{\circ}$ and 60 levels from the surface to $0.01 \mathrm{hPa}$ in runs "A_E40" and "B_EI". These were integrated 
Table 1. TOMCAT model experiments.

\begin{tabular}{|c|c|c|c|c|c|c|}
\hline Run & Resolution & Meteorological analysis & Convection & $\begin{array}{l}\text { Evaporation } \\
\text { flux }\end{array}$ & $\mathrm{Rn}$ & Period \\
\hline "A_E40" & $2.8^{\circ} \times 2.8^{\circ} \mathrm{L} 60$ & T42 ERA-40/Operational & SC1999 - Tiedtke & UGCM & Yes & 1989-2005 \\
\hline "B_EI" & $2.8^{\circ} \times 2.8^{\circ} \mathrm{L} 60$ & T42 ERA-Interim & SC1999 - Tiedtke & UGCM & Yes & 1989-2005 \\
\hline "C_E40noconv" & $2.8^{\circ} \times 2.8^{\circ} \mathrm{L} 60$ & T42 ERA-40/Operational & No & UGCM & Yes & 1989-2005 \\
\hline "D_EInoconv" & $2.8^{\circ} \times 2.8^{\circ} \mathrm{L} 60$ & T42 ERA-Interim & No & UGCM & Yes & 1989-2005 \\
\hline "E_EInewevap" & $2.8^{\circ} \times 2.8^{\circ} \mathrm{L} 60$ & T42 ERA-Interim & SC1999 - Tiedtke & $1 \times 1$ & Yes & 1989-2005 \\
\hline "F_EInewconv" & $2.8^{\circ} \times 2.8^{\circ} \mathrm{L} 60$ & T42 ERA-Interim & Updated Tiedtke & $1 \times 1$ & Yes & 1989-2005 \\
\hline “G_5.6” & $5.6^{\circ} \times 5.6^{\circ} \mathrm{L} 60$ & T42 Operational & SC1999 - Tiedtke & $1 \times 1$ & Yes & 2005 \\
\hline "H_1.1" & $1.1^{\circ} \times 1.1^{\circ} \mathrm{L} 60$ & T42 Operational & SC1999 - Tiedtke & $1 \times 1$ & No & 2005 \\
\hline "I_1.4" & $1.4^{\circ} \times 1.4^{\circ} \mathrm{L} 60$ & T42 Operational & SC1999 - Tiedtke & $1 \times 1$ & No & 2005 \\
\hline "J_T106" & $1.1^{\circ} \times 1.1^{\circ} \mathrm{L} 60$ & T106 Operational & SC1999 - Tiedtke & $1 \times 1$ & Yes & 2005 \\
\hline "K_L31" & $2.8^{\circ} \times 2.8^{\circ} \mathrm{L} 31$ & T42 Operational & SC1999 - Tiedtke & UGCM & Yes & 2005 \\
\hline "L_2EVAP" & $2.8^{\circ} \times 2.8^{\circ} \mathrm{L} 60$ & T42 ERA-Interim & SC1999 - Tiedtke & $2 \times \mathrm{UGCM}$ & No & 2005 \\
\hline "M_0EVAP" & $2.8^{\circ} \times 2.8^{\circ} \mathrm{L} 60$ & T42 ERA-Interim & SC1999 - Tiedtke & 0 & No & 2005 \\
\hline “N_1991” & $2.8^{\circ} \times 2.8^{\circ} \mathrm{L} 31$ & T42 Operational & SC1999 - Tiedtke & UGCM & No & 1990-1991 \\
\hline "O_EIar" & $2.8^{\circ} \times 2.8^{\circ} \mathrm{L} 60$ & T42 ERA-Interim & ERA-Interim archive & & Yes & 2005 \\
\hline "P_det" & $2.8^{\circ} \times 2.8^{\circ} \mathrm{L} 31$ & T42 Operational & Barret et al. (2010) & UGCM & Yes & 2005 \\
\hline
\end{tabular}

from 1989 to 2005 using ERA-40 (ECMWF operational analyses after 2001) and ERA-Interim reanalyses, respectively. These runs used the default model convection scheme with surface evaporation fluxes from the UGAMP GCM (UGCM). Runs "C_E40noconv" and "D_EInoconv" were the same as runs "A_E40" and "B_EI", respectively, but without convection. Run "E_EInewevap" was the same as run "B_EI", but used the high resolution surface evaporation fields. Run "F_EInewconv" was the same as run "B_EI", but used the updated version of the Tiedtke scheme.

A number of shorter sensitivity runs were performed for 2005. Runs "G_5.6", "I_1.4", and "H_1.1", were similar to "E_EInewevap" but had horizontal resolutions of 5.6, $1.4^{\circ}$ and $1.1^{\circ}$, respectively. All of these runs were forced using T42 ECMWF analyses. Run "J_T106" was the same as "H_1.1" $\left(1.1^{\circ} \times 1.1^{\circ}\right.$ horizontal resolution) but used T106 ECMWF analyses. Note that TOMCAT reads in winds as spectral coefficients of vorticity and divergence. These are then averaged onto whatever model grid is being used as part of the spectral transform. If the forcing winds are higher resolution than the model grid then information from the higher wavenumbers is not used - the spectral coefficients are truncated.

Runs "L_2EVAP" and "M_OEVAP" were similar to run "B_EI" but used 2 or 0 times the UGCM surface evaporation flux. Run "N_1991" was performed in order to compare our results with those of SC1999. This run used the same version of the model as our default experiments (e.g. runs "A_E40" and "B_EI") but used identical ECMWF L31 operational winds from 1990/91 as SC1999. Run "K_L31" was the same as run "A_E40" (for 2005) but used 31 levels to $10 \mathrm{hPa}$. Note that run "K_L31" is the TOMCAT simula- tion analysed in the model intercomparison paper of Hoyle et al. (2010). Run "P_det" is the same as run "K_L31" but employed updates to the basic TOMCAT Tiedtke scheme designed to increase convective transport to the mid and upper troposphere. In Run "P_det", detrainments are assumed to be at the top layer rather than in each layer between cloud top and bottom as in the default version, to allowing maximum lift for tracers from boundary layer. These updates were used in the pTOMCAT runs of Barrett et al. (2010) and involve reducing the entrainment/detrainment rates to half the values suggested by Tiedtke (1989) and using ISCCP data (Rossow et al., 1996) to specify the fraction of saturated water vapour in the near-surface model grid boxes. The aim of decreasing the entrainment/detrainment rates is to reduce the mixing of stable environmental air into the cloud and thus maintain positive buoyancy to higher altitudes within the cloud. This will offset the problem in off-line models of diagnosing convection with analyses that have already been convectively adjusted. The use of ISCCP data should give a more realistic distribution of triggered convection.

Finally, run "O_EIar" is a new version of the TOMCAT model which reads in 6-hourly archived convective mass fluxes from ERA-Interim reanalyses. Note that the convective mass fluxes are read in on a $1^{\circ} \times 1^{\circ}$ grid. These are then averaged onto the model grid employed in a way which conserves the total mass transport in the analyses. 


\section{Datasets}

\subsection{ECMWF reanalyses}

We have used the archived ECMWF convective mass fluxes to compare with values calculated within our CTM or, in some experiments, to force the CTM. Convective mass fluxes are not saved in the operational ECMWF analyses but are only stored from the lower resolution reanalyses such as ERA-40 and ERA-Interim. In the ECMWF archive the accumulated updraft/downdraft convective mass fluxes and updraft/downdraft detrainment rates are saved at four forecast steps (3, 6, 9 and 12) from 0:00 and 12:00 UTC. We use these accumulated fields (at horizontal resolution of $1^{\circ} \times 1^{\circ}$ ) for the 6- and 12-h forecasts to create average 6-hourly convective fields.

\subsection{Cloud top height measurements}

MODIS (Moderate Resolution Imaging Spectroradiometer) on the NASA Earth Observing System (EOS) Terra and Aqua platforms provides measurements for deriving global and regional cloud properties (Menzel et al., 2008). The cloud-top pressure and effective cloud amount are determined using radiances measured in spectral bands located within the broad $15 \mu \mathrm{m} \mathrm{CO} 2$ absorption region. Here we use the Level-3 MODIS Atmosphere Monthly Global Product from the Terra platform which contains roughly 800 statistical datasets that are derived from the Level-3 MODIS Atmosphere Daily Global Product. The data is available from July 2002 from (ftp://ladsweb.nascom.nasa.gov/allData/51/ MYD08_M3/). We convert cloud top pressure to cloud top height assuming a surface pressure of $1000 \mathrm{hPa}$ and a scale height of $7 \mathrm{~km}$.

\subsection{Convective precipitation}

Apart from the widely used simulated precipitation fields from NWP models (e.g, NCEP, ECMWF), there are some other useful precipitation datasets sources.

GPI rainfall data are IR satellite-based rainfall estimates which are an intermediate product of the Global Precipitation Climatology Project (GPCP) (Arkin and Meisner, 1987). GPI is a precipitation estimation algorithm which estimates tropical rainfall using cloud-top temperature as the sole predictor. Numerous studies have shown that the GPI yields useful results in the tropics and warm-season extratropics. The major advantage of the technique is that it is based on IR data which is available frequently over most areas of the globe from geostationary and polar orbiting satellites. The major weakness of the method is that estimation of precipitation from cloud-top temperature is relatively far removed from the physics of the precipitation generation process (for more information see www.cpc.ncep.noaa.gov and Morrissey and Greene, 1993).
Xie and Arkin (1997) constructed a global monthly mean precipitation analyses dataset CMAP (CPC Merged Analysis of Precipitation) by merging several kinds of individual data sources with different characteristics including gaugebased monthly analyses from the Global Precipitation Climatology Centre and a number of satellite estimates, including the IR-based GPI, OLR-based OPI, MSU-based Spencer, NW-scattering-based NOAA/NESDIS and the NWemission-based change and precipitation forecasts from the NCEP-NCAR reanalysis.

\subsection{Radon measurements and emissions}

Radon $\left({ }^{222} \mathrm{Rn}\right)$ is a radioactive inert gas which enters the atmosphere at ground level, where it is formed by the radioactive decay of the trace quantities of uranium found naturally in rocks and soils. It has no chemical activity and is not subject to wet or dry deposition (e.g., Jacob and Prather, 1990; Josse et al., 2004). Because it is inert, and not scavenged by precipitation, the only significant removal mechanism for atmospheric radon is its own radioactive decay, which occurs with a half-life of 3.8 days. Hence, radon is an interesting trace atmospheric constituent for studying transport in the troposphere. It has been widely used to evaluate the tracer transport in global models (e.g., Jacob et al., 1997; Stevenson et al., 1998; Stockwell and Chipperfield, 1999; Taguchi et al., 2002; Josse et al., 2004; Zhang et al., 2008). As discussed in these studies, ${ }^{222} \mathrm{Rn}$ emissions vary in time and space. Here we use the same radon source function as Jacob et al. (1997). The Radon flux is 1.0 atom $\mathrm{cm}^{-2} \mathrm{~s}^{-1}$ over land between $60^{\circ} \mathrm{S}-60^{\circ} \mathrm{N} ; 0.005$ atoms $\mathrm{cm}^{-2} \mathrm{~s}^{-1}$ over oceans between $60^{\circ} \mathrm{S}-60^{\circ} \mathrm{N}$; 0.005 atoms $\mathrm{cm}^{-2} \mathrm{~s}^{-1}$ between $60^{\circ}$ and $70^{\circ}$ latitude in both hemispheres and zero polewards of $70^{\circ}$. The ${ }^{222} \mathrm{Rn}$ data used here are based on in situ measurements in the atmospheric surface layer at different continental, oceanic and coastal sites and observed campaign profiles. For more details concerning the ${ }^{222} \mathrm{Rn}$ data see Zhang et al. (2008).

\section{Results}

\subsection{Updraft convective mass fluxes}

Updraft mass flux is one of the important convective parameters which is now available from some NWP archives. Kain et al. (2002) pointed out that updraft mass flux is able to provide a unique prediction of convective intensity. In this section we compare the archived updraft convective mass fluxes from ECMWF ERA-40 and ECMWF-Interim reanalyses with the calculations from our TOMCAT experiments. 

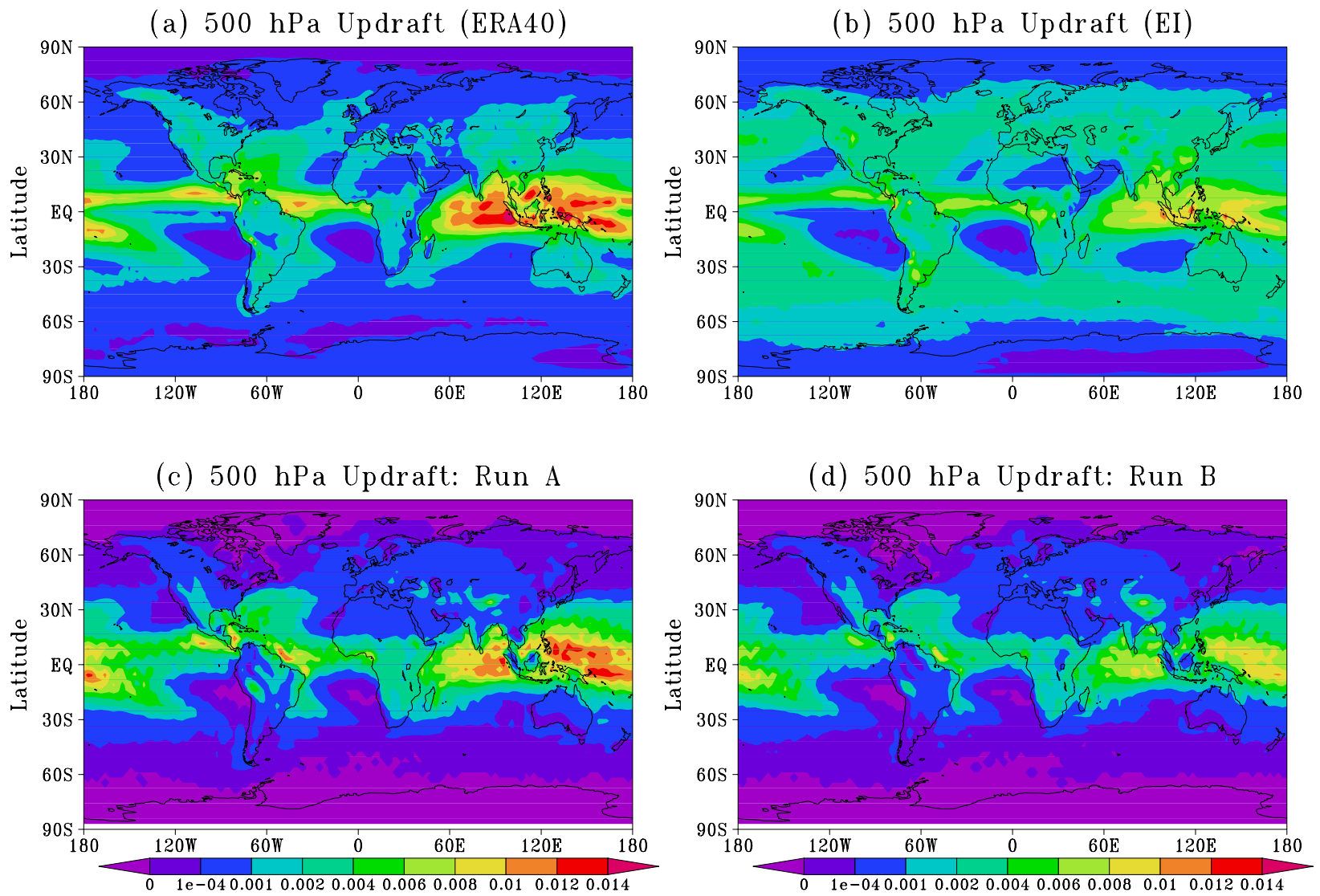

Fig. 1. Climatological convective updraft mass flux $\left(\mathrm{kg} \mathrm{m}^{-2} \mathrm{~s}^{-1}\right)$ at $500 \mathrm{hPa}$ averaged from (a) ERA-40 reanalyses (1989-2001), (b) ERAInterim reanalyses (1989-2005), (c) run “A_E40” (1989-2005), and (d) run “B_EI” (1989-2005).

\subsubsection{Comparison of archived updraft convective mass flux with basic TOMCAT simulations}

Figure 1 shows the climatological convective updraft mass flux at $500 \mathrm{hPa}$ averaged from archived ERA-40 (1989-2001) and ERA-Interim (1989-2005) reanalyses as well as the basic TOMCAT simulations which are forced by ERA-40 (ECMWF operational analyses after 2001) and ERA-Interim reanalyses, respectively. The ECMWF archived mass fluxes show strong convection in the tropics especially around the South East Asia region. The ECMWF-Interim reanalyses have less convective updraft mass flux than ERA-40. The basic TOMCAT simulations forced by ERA-40 and ERAInterim both capture the climatological convection quite well and also reproduce the ERA-40 - ERA-Interim mass fluxes differences.

Figure 2 compares time series of the zonal mean updraft convective mass fluxes at $500 \mathrm{hPa}$ from ERA-40 and ERAInterim reanalyses and TOMCAT runs "A_E40" and "B_EI". At this altitude the model captures the annual cycle and latitudinal variation in the tropical convection. This figure again highlights that there are significant differences in the archived convective mass fluxes between the two ECMWF datasets. The two basic model runs capture these differences but underestimate the archived mass flux values. Note the large change in modelled convection in run "A_E40" in 2002 when ERA-40 analyses change to operational ones. Clearly, the performance of the model convection scheme changes strongly with the analyses used to force the model.

\subsubsection{Impact of TOMCAT sensitivity experiments on updraft mass flux}

Figures 3 and 4 compare the JJA and DJF averaged zonal mean upward mass fluxes from archived 6-hourly ERA40 and ERA-Interim reanalyses and calculated in selected TOMCAT experiments. The ECMWF archived mass fluxes show the expected behaviour of convection: there is maximum updraft mass flux in the lower levels and larger values in the tropical region. There is also stronger convection in summer. Note that in the tropics these archived mass fluxes indicate that significant convective transport extends up to nearly $\sim 100 \mathrm{hPa}$, i.e. the tropopause region. The ERA40 and ERA-Interim reanalyses show similar mass flux distributions but there are differences in detail. For example, ERA-Interim gives smaller average convective transport in the tropics. 
(a) Zonal mean Updraft (ERA40):500hPa

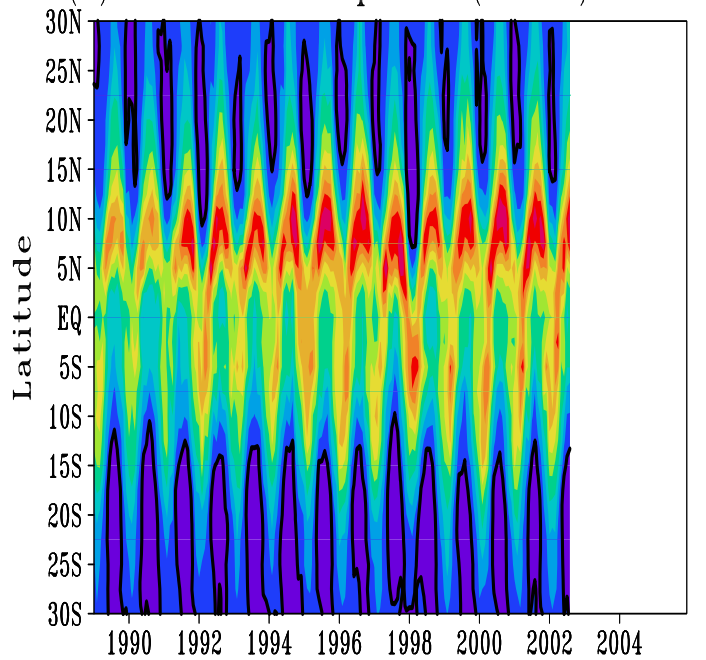

(c) Run A

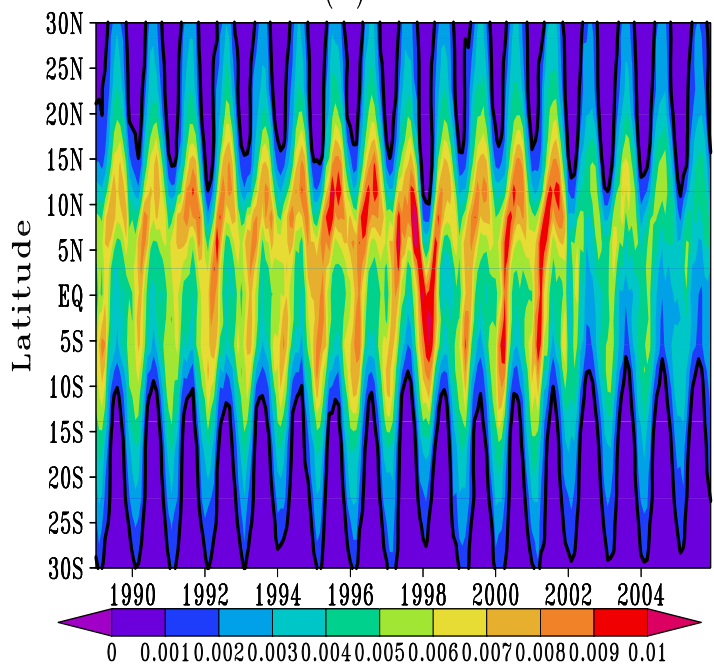

(b) ERA-Interim

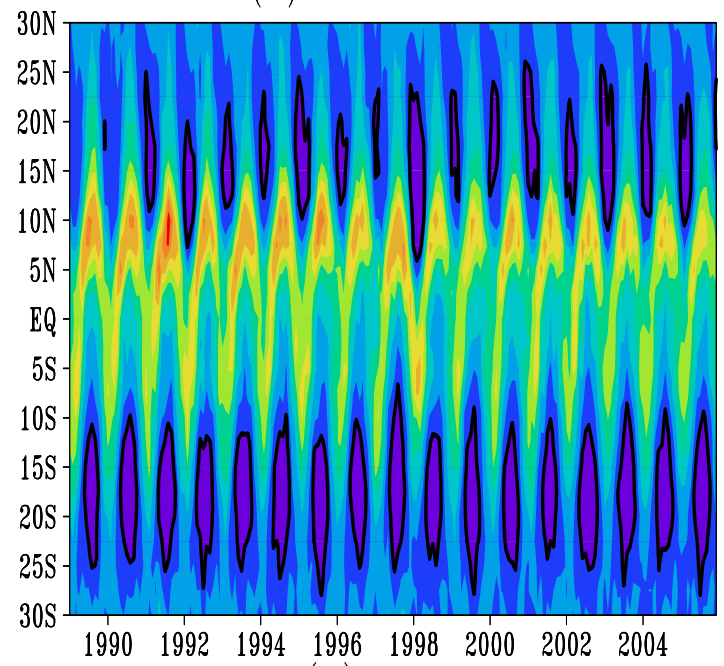

(d) Run B

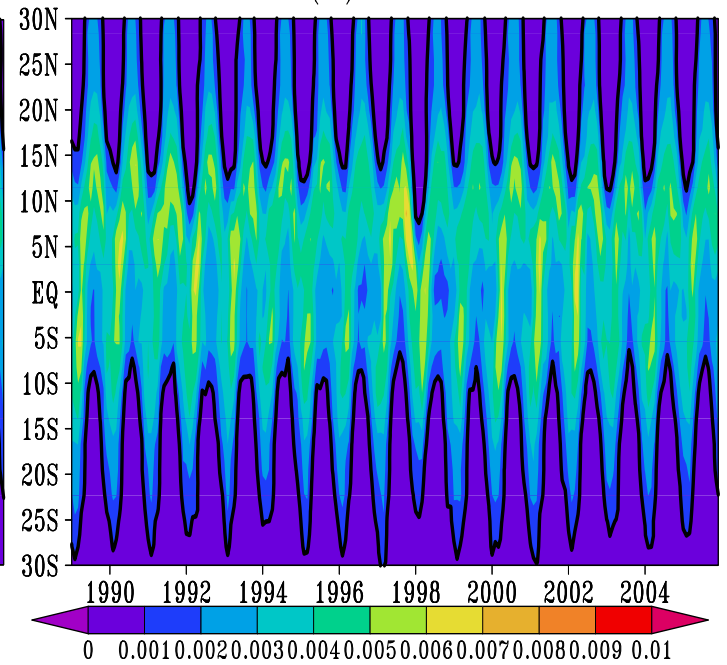

Fig. 2. Time series of zonal mean monthly mean updraft convective mass flux $\left(\mathrm{kg} \mathrm{m}^{-2} \mathrm{~s}^{-1}\right)$ at $500 \mathrm{hPa}$ from (a) ERA-40 reanalyses, (b) ERA-Interim reanalyses, (c) Run “A_E40" (forced by operational winds from 2002 onwards), and (d) Run "B_EI". The bold contour indicates $0.001 \mathrm{~kg} \mathrm{~m}^{-2} \mathrm{~s}^{-1}$.

The diagnosed mean upward mass flux distributions from the four TOMCAT runs shown in Figs. 3 and 4 agree reasonably well with the ECMWF reanalysis data below $200 \mathrm{hPa}$ in the tropics. However, the most obvious disagreement is that the reanalyses show strong convective transport up to $100 \mathrm{hPa}$, i.e. well into the TTL, which is not captured by any of these TOMCAT runs (e.g. compare altitude of $0.001 \mathrm{~kg} \mathrm{~m}^{-2} \mathrm{~s}^{-1}$ contour). The model also underestimates the convective mass flux in the mid-high latitudes.

When forced using different analyses the model does capture differences between ERA-40 and ERA-Interim archived mass fluxes. Run "A_E40" (forced by ERA-40) gives stronger tropical convection below $200 \mathrm{hPa}$ than run "B_EI" (forced by ERA-Interim). This is due to differences in the large-scale wind, temperature and humidity fields which drive the CTM. Run "E_EInewevap" is the same as run "B_EI" but uses higher horizontal surface evaporation fluxes. This data gives stronger convection below $400 \mathrm{hPa}$ but there is little difference at higher altitudes in the tropics.

The basic TOMCAT convection scheme does not include downdrafts and mid-level convection. We have tested the inclusion of these processes in model run "FEInewconv". These make a significant difference to the calculated mass fluxes in mid latitudes (compare runs "E_EInewevap" and "F_EInewconv") which improves agreement with the archived ECMWF fluxes. Note that there is less asymmetry of the weaker updraft contours between the northern and southern hemispheres in run "F_EInewconv". This is partly due to the criteria for the mid-level convection used in the Tiedkte (1989) scheme, 

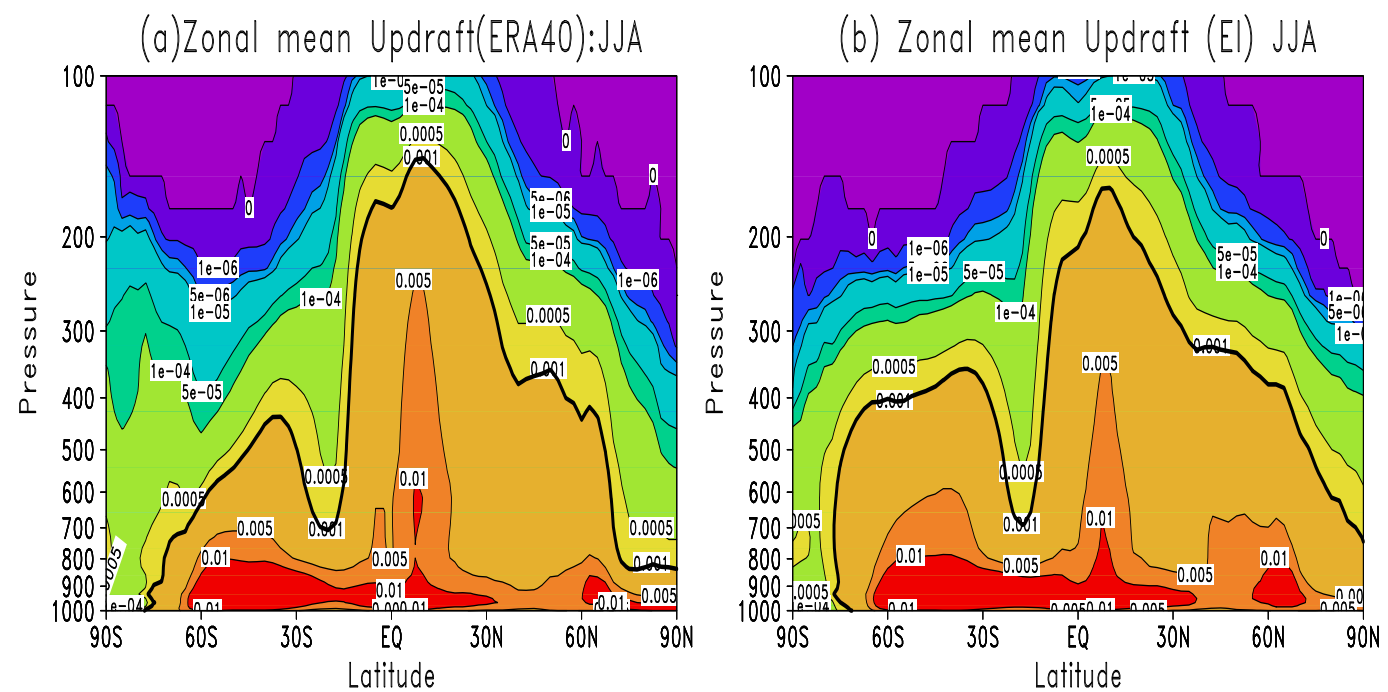

(c) Zonal mean Updraft JJA: Run A
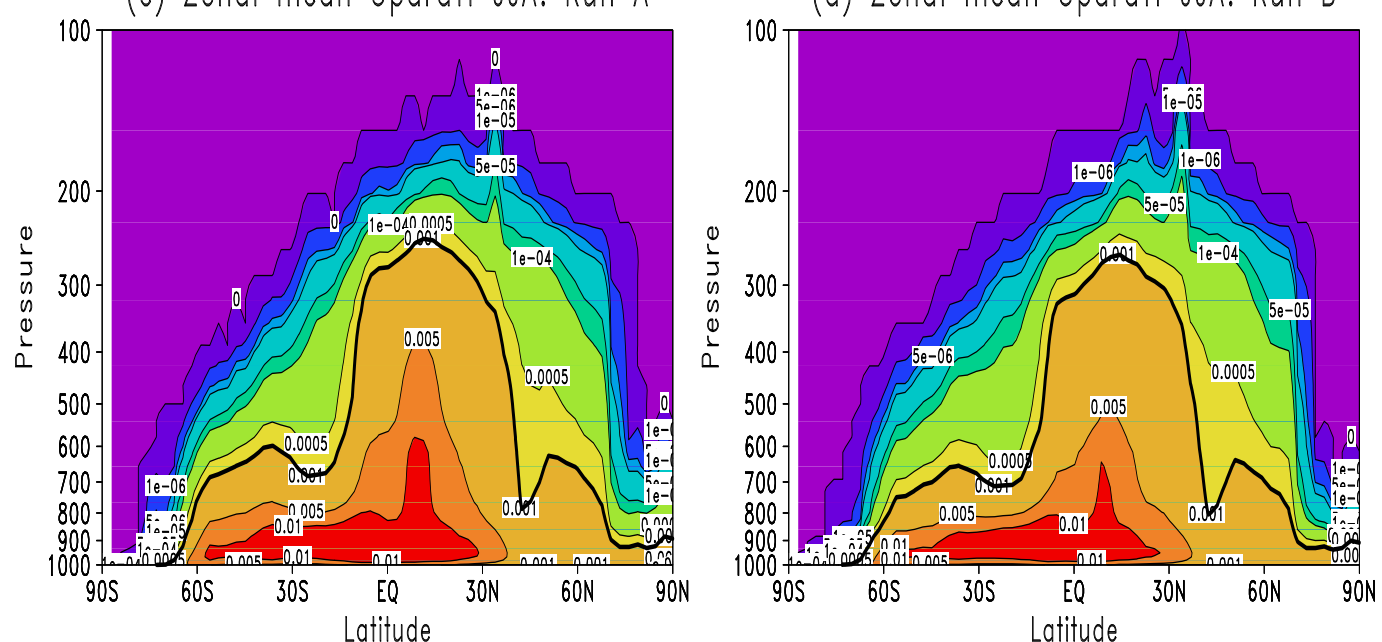

(e) Zonal mean Updraft JJA: Run E

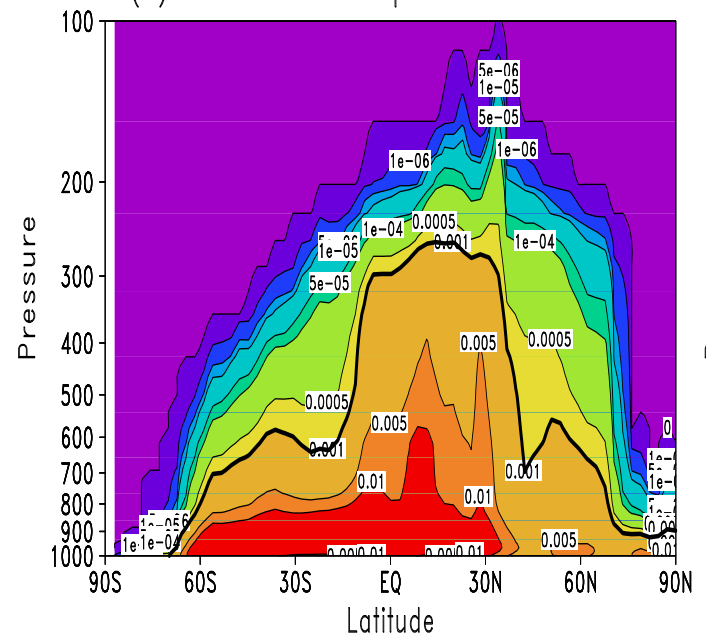

(f) Zonal mean Updraft JJA: Run F

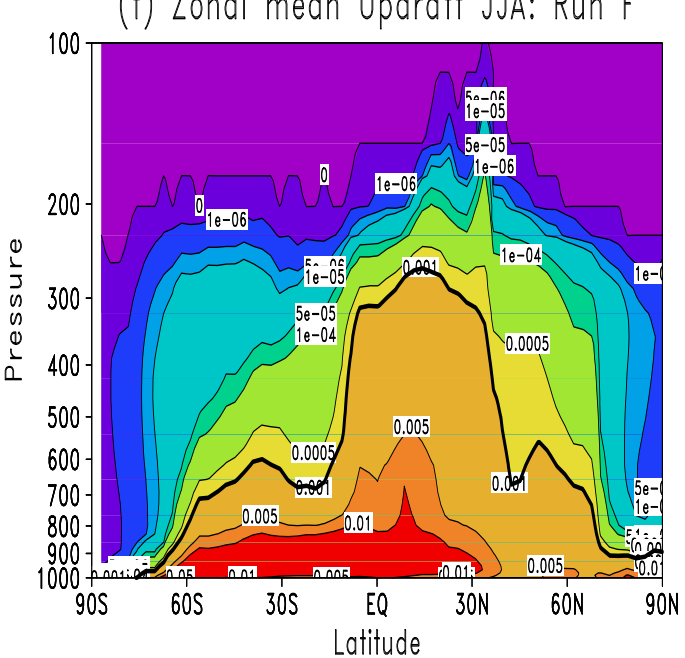

Fig. 3. Zonal mean convective updraft mass flux $\left(\mathrm{kg} \mathrm{m}^{-2} \mathrm{~s}^{-1}\right.$ ) averaged for JJA from (a) ERA-40 reanalyses (1989-2001), (b) ERA-Interim reanalyses (1989-2005), (c) run "A_E40" (1989-2005), (d) run "B_EI" (1989-2005), (e) run "E_EInewevap" (1989-2005), and (f) run "F_EInewconv" (1989-2005). The bold contour indicates $0.001 \mathrm{~kg} \mathrm{~m}^{-2} \mathrm{~s}^{-1}$. 

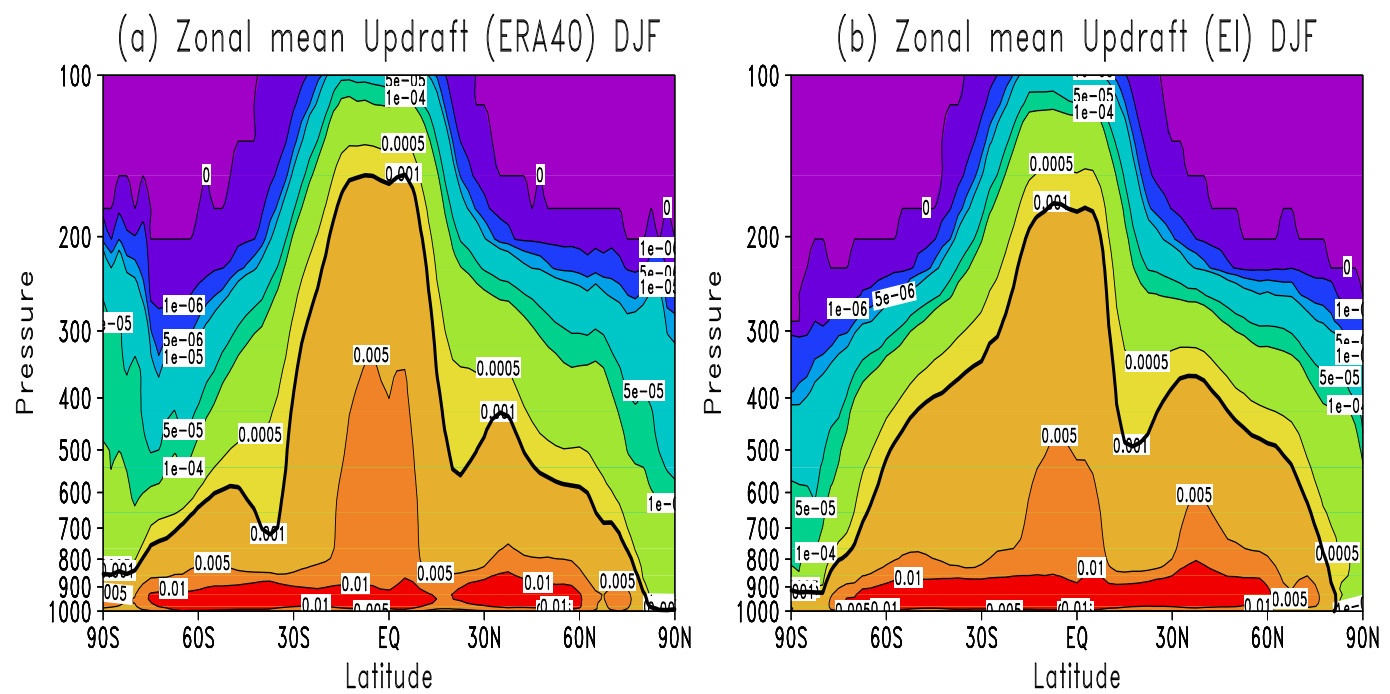

(c) Zonal mean Updraft DJF: Run A

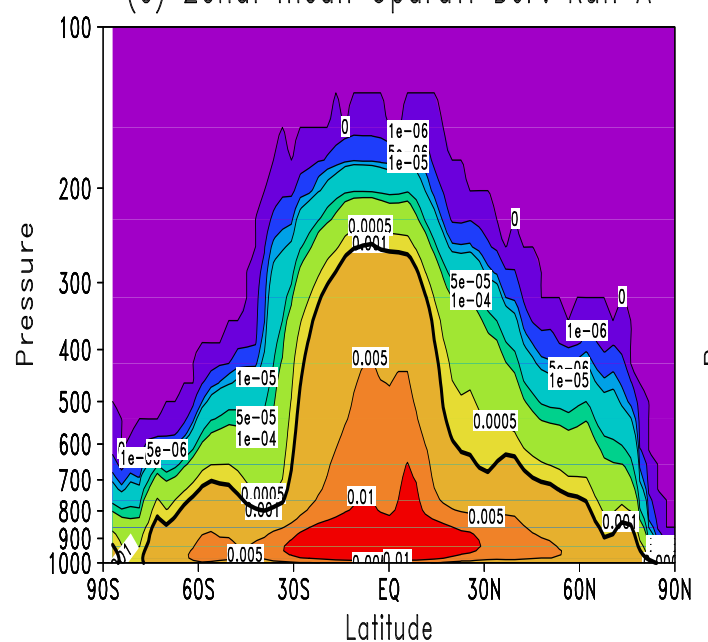

(d) Zonal mean Updraft DJF: Run B

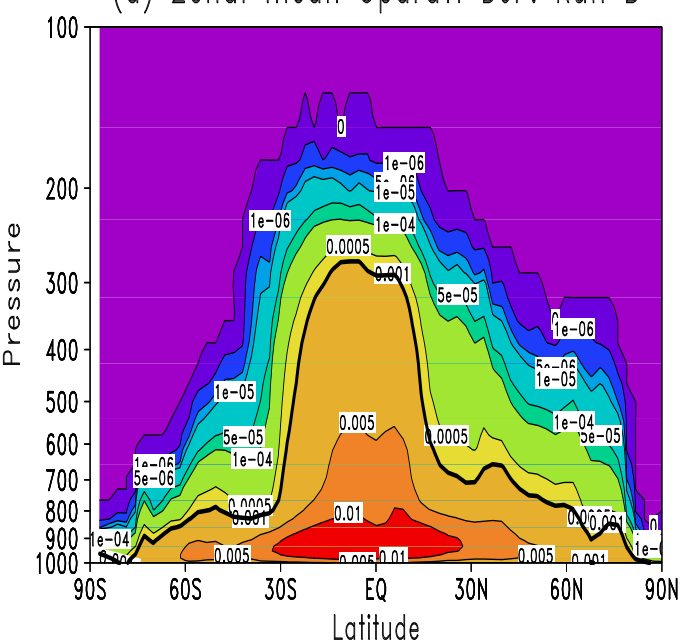

(e) Zonal mean Updraft DJF: Run E

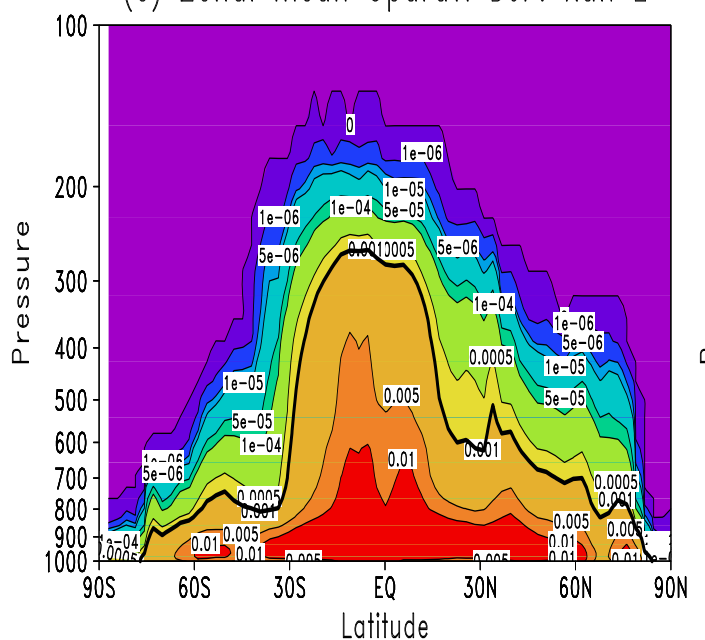

(f) Zonal mean Updraft DJF: Run F

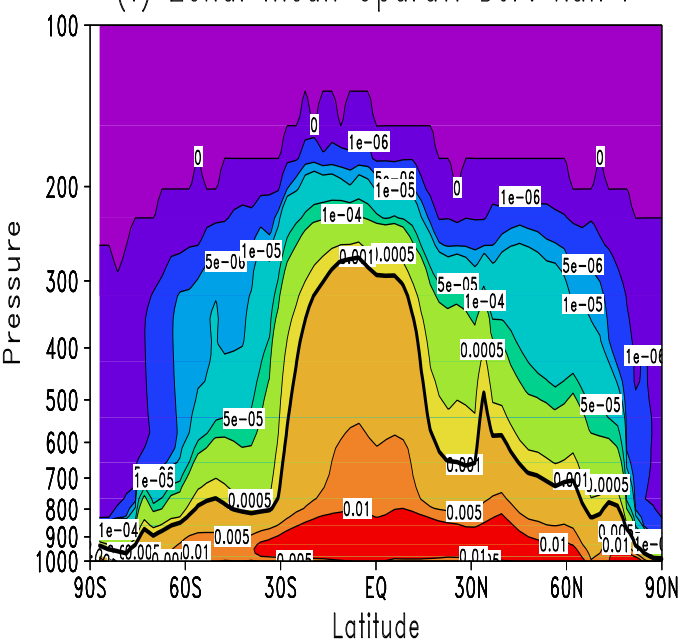

Fig. 4. As Fig. 3, but for DJF. 


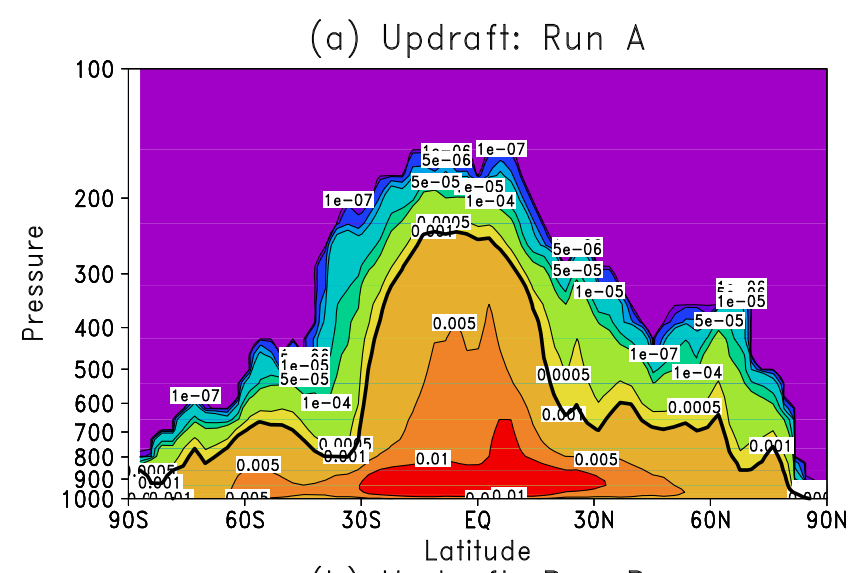

(b) Updraft: Run B

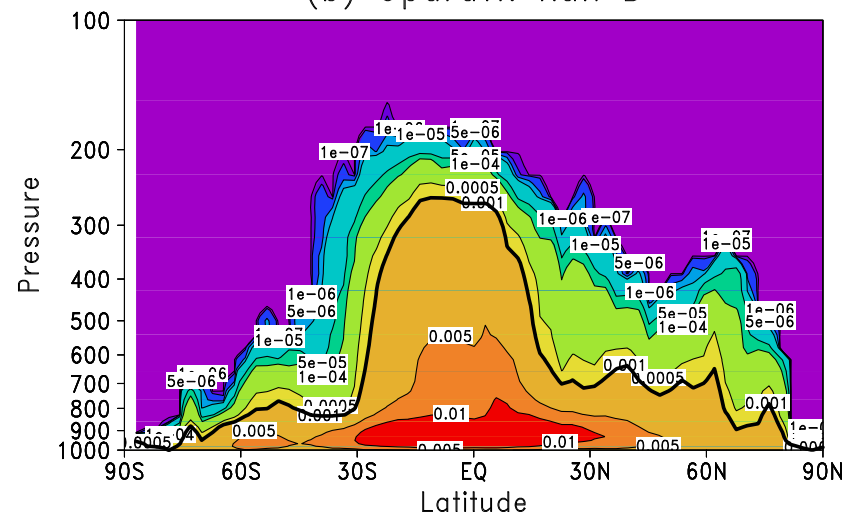

(c) Updraft: Run $\mathrm{N}$

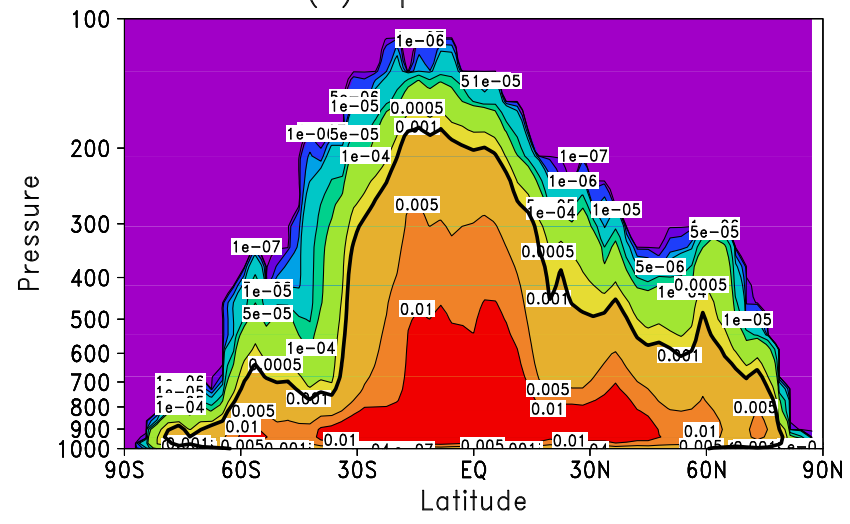

Fig. 5. Zonal mean convective updraft mass flux $\left(\mathrm{kg} \mathrm{m}^{-2} \mathrm{~s}^{-1}\right)$ for runs (a) "A_E40", (b) "B_EI", and (c) "N_1991" averaged from 27 December 1990-11 January 1991. The bold contour indicates $0.001 \mathrm{~kg} \mathrm{~m}^{-2} \mathrm{~s}^{-1}$.

which requires large-scale ascent and an environment relative humidity of more than $90 \%$. However, on average run "F_EInewconv" has less convective mass flux in the tropical low troposphere than "E_EInewevap" and shows no improvement in the tropical UT.

Therefore, there is clearly a difference between diagnosed convective mass fluxes in TOMCAT and the archived ECMWF reanalyses. The previous detailed analysis of the
TOMCAT convection scheme was performed by SC1999 where, based on short model runs, they concluded the model performed well. In order to compare our results with SC1999 we performed a run with the current version of TOMCAT using the 1990/91 L31 operational ECMWF winds used by SC1999. Figure 5 compares results from this run "N_1991" with the two runs of the same model version which use the reanalysis data (runs "A_E40" and "B_EI") averaged over the same period. The tropical convective mass fluxes are larger in the mid troposphere in run "N_1991" and extend slightly higher. Therefore, results of the CTM convection scheme do vary with different forcing datasets and older operational winds appear to give stronger tropical convection than the ERA-40 reanalyses. This illustrates possible dangers of comparing results from different experiments of the same CTM or of using results from an evaluation of the CTM during one period to explain results during another. However, despite the slightly stronger convection in run "N_1991", again the diagnosed convection does not extend as high in the tropics as indicated by the ECMWF reanalysis data.

The TOMCAT results presented so far have used a horizontal model resolution of $2.8^{\circ} \times 2.8^{\circ}$ and T42 (re)analyses. The resolution of both the model and the winds used to force it might be expected to impact on the diagnosed convection in the CTM; higher resolution might trigger more convective events.

Figure 6 shows results from model sensitivity runs which investigate the effect of resolution in both the CTM and the forcing meteorology. On degrading the resolution of the model and forcing analyses from $2.8^{\circ} \times 2.8^{\circ}$ (run "E_EInewevap") to $5.6^{\circ} \times 5.6^{\circ}$ (run "G_5.6"), the CTM produces less convective transport. Note that run "E_EInewevap" uses ERA-Interim reanalyses while the others use operational forcing files. However, the change is not large compared to model versus archived mass flux differences. Similarly, on increasing the model resolution to $1.4^{\circ} \times 1.4^{\circ}$ (run "I_1.4") and $1.1^{\circ} \times 1.1^{\circ}$ (run "H_1.1"), but with T42 analyses, although the diagnosed mass fluxes are larger, the calculated convection is similar. Finally, for the high resolution model $\left(1.1^{\circ} \times 1.1^{\circ}\right)$ increasing the forcing analyses from T42 to T106 (runs "J_T106" versus "H_1.1") there is a further small increase in convective mass fluxes. Overall, however, the impact of large changes in resolution are small and do not really improve on the most significant discrepancies with the archived mass fluxes in the tropical upper troposphere and at high latitudes.

Figure 6 also shows results from runs "L_2EVAP" and "M_OEVAP" which investigate the sensitivity of the diagnosed convection to large changes in the surface evaporation flux. These changes to the evaporation flux have large impacts on the modelled convection in the lower troposphere and in the tropical mid-troposphere, i.e. shallow convection. However, even the extreme case of doubling the surface evaporation flux does not significantly change the modelled convective transport to the tropical UT. 
(a) ERA-Interim

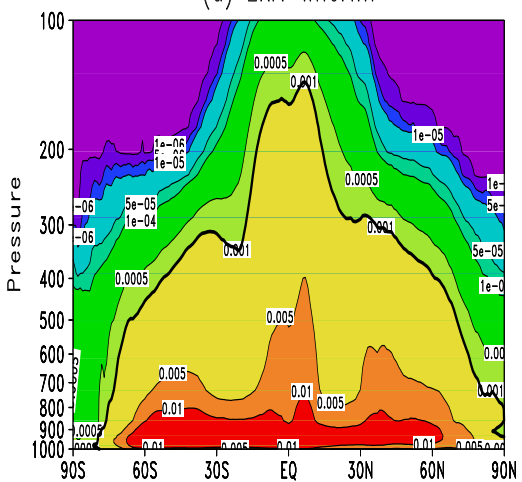

(d) Run H

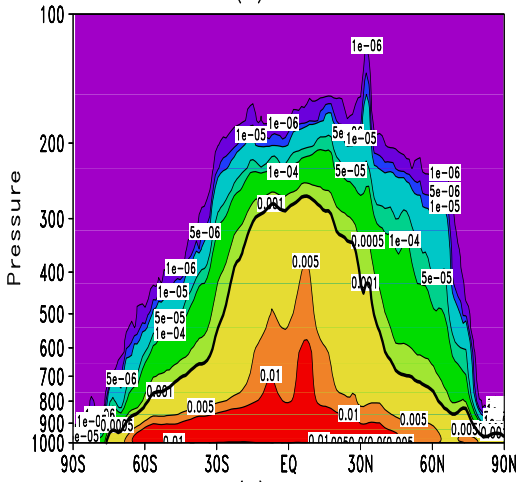

(g) Run L

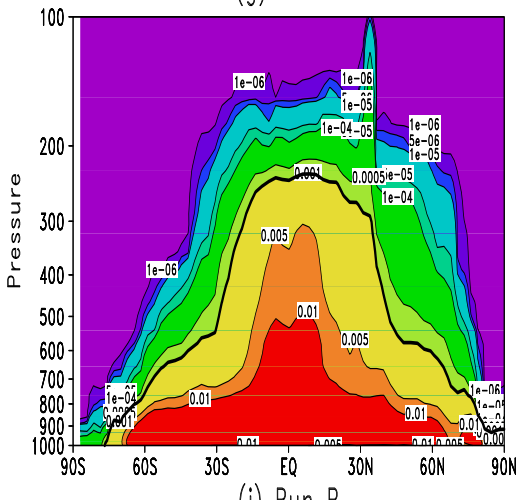

(i) Run P

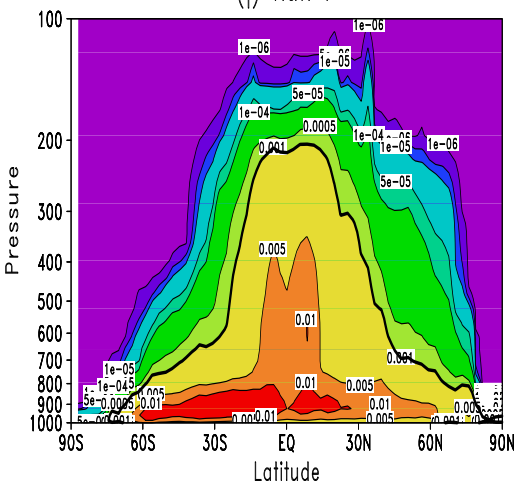

(b) Run E

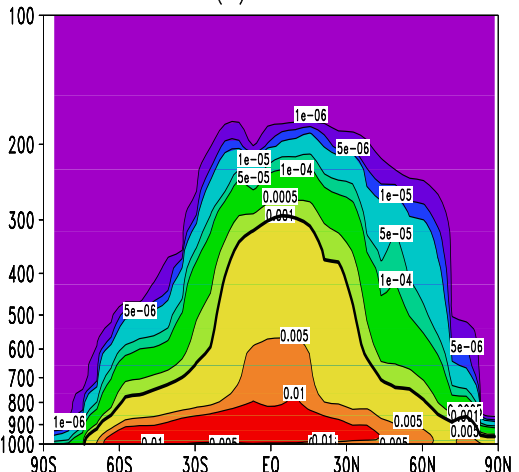

(e) Run I

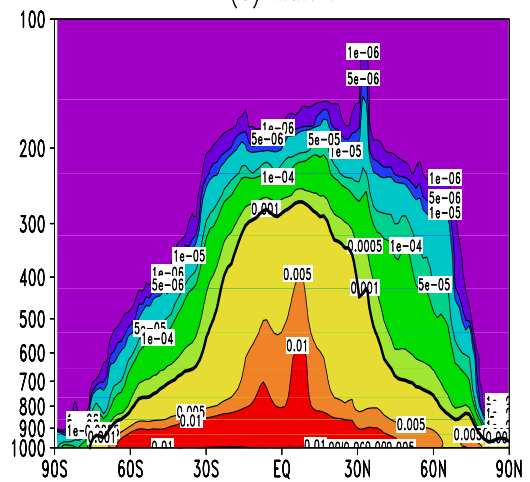

(h) Run M

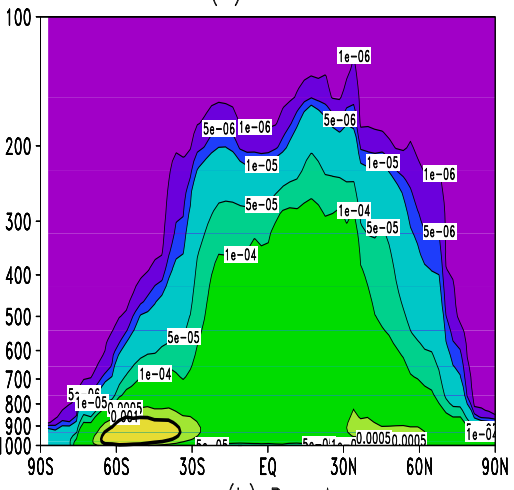

(k) Run A

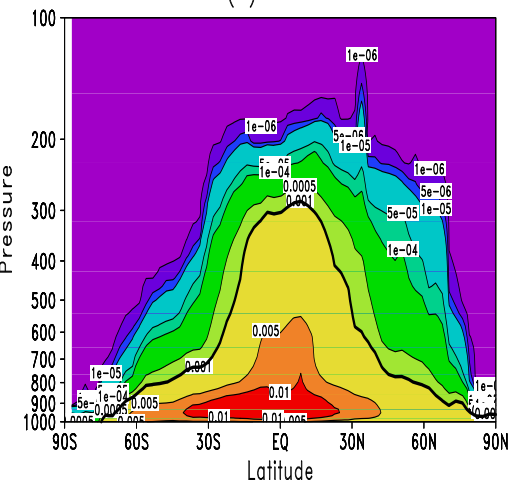

(c) Run G

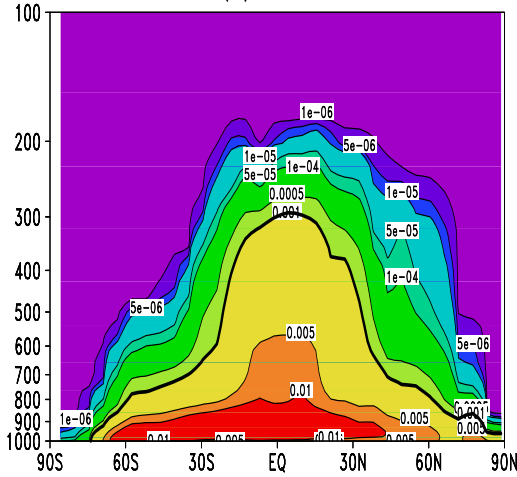

(f) Run J

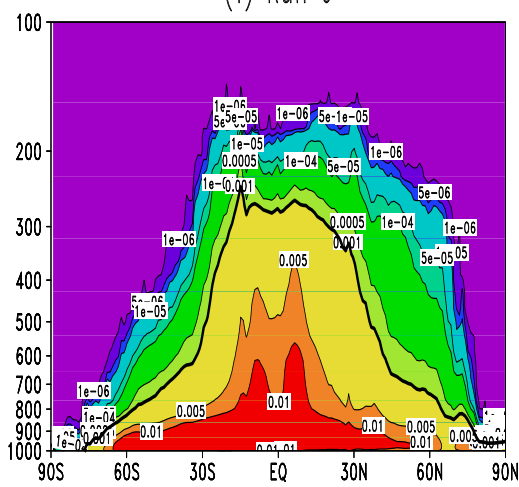

(i) Run 0

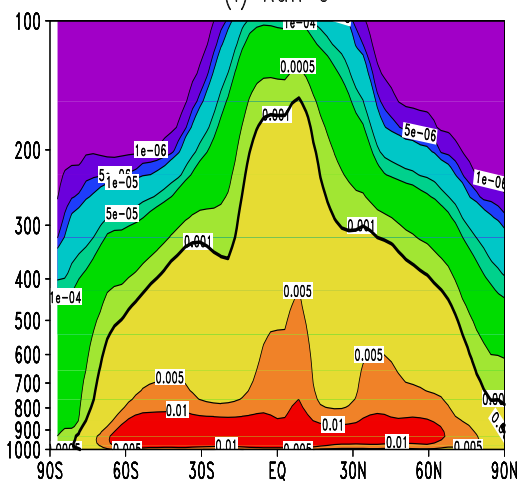

(I) Run K

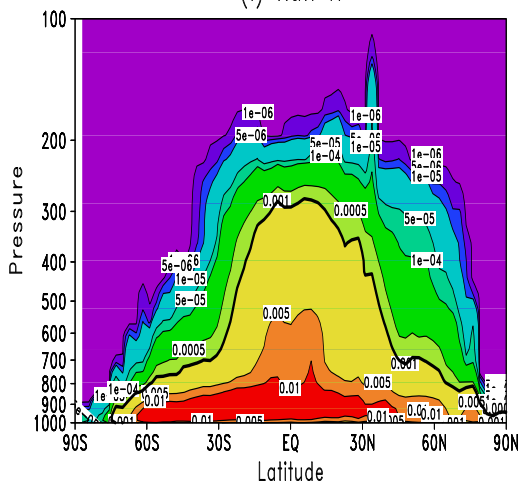

Fig. 6. Zonal mean annual mean convective updraft mass flux $\left(\mathrm{kg} \mathrm{m}^{-2} \mathrm{~s}^{-1}\right)$ for 2005 for (a) ERA-Interim reanalyses $\left(1^{\circ} \times 1^{\circ}\right.$ grid), (b) run "E_EInewevap", (c) run "G_5.6", (d) run "H_1.1", (e) run "I_1.4", (f) run "J_T106", (g) run "L_2EVAP", (h) run "M_0EVAP", (i) run "O_EIar", (j) run "P_det", (k) run "A_E40", and (l) run "K_L31". The bold contour indicates $0.001 \mathrm{~kg} \mathrm{~m}^{-2} \mathrm{~s}^{-1}$. 
(a) Tropical Updraft mass flux:2005

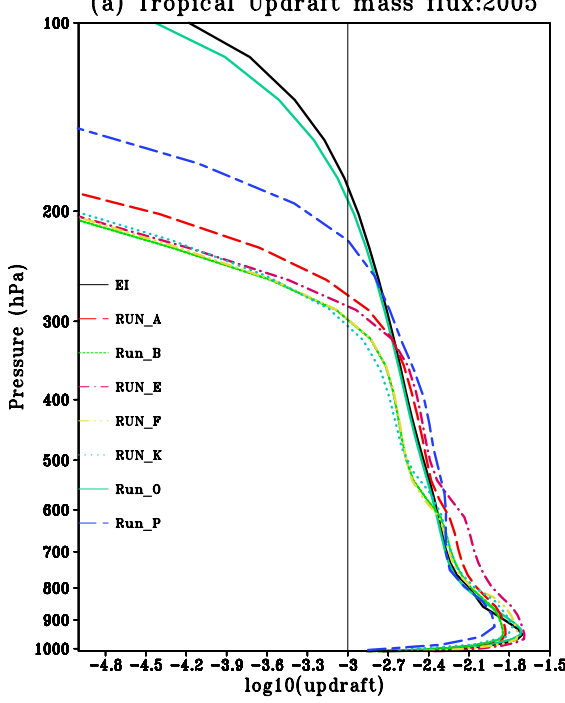

(b) Tropical Updraft mass flux:2005

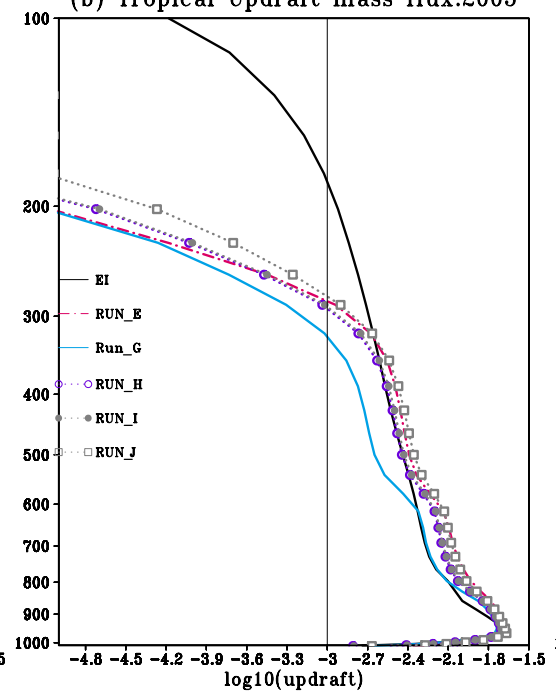

(c) Tropical Updraft mass flux:2005

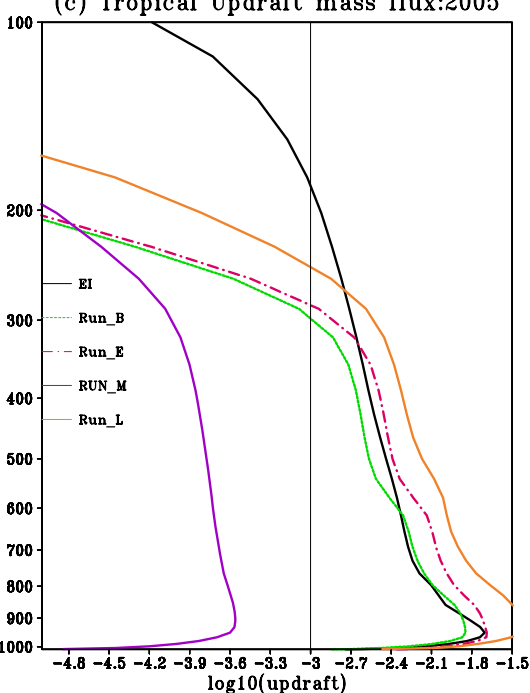

Fig. 7. Zonal mean annual mean tropical $\left(25^{\circ} \mathrm{S}-25^{\circ} \mathrm{N}\right)$ updraft convective mass flux $\left(\mathrm{kg} \mathrm{m}^{-2} \mathrm{~s}^{-1}\right)$ for 2005 from ERA-Interim reanalyses and (a) runs "A_E40", "B_EI", "E_EInewevap", "F_EInewconv", "K_L31”, "N_1991” (December 1990 to January 1991), "O_EIar", "P_det", (b) runs "E_EInewevap", “G_5.6”, "H_1.1”, "I_1.4”, "J_T106”, and (c) runs "B_EI”, "E_EInewevap”, "L_2EVAP”, "M_0EVAP”.

Model run "P_det" included changes to the TOMCAT convection scheme aimed at increasing tracer transport to the mid/upper tropical troposphere. In this run the annual mean, zonal mean convection does extend higher (e.g. the $0.001 \mathrm{~kg} \mathrm{~m}^{-2} \mathrm{~s}^{-1}$ contour reaches $200 \mathrm{hPa}$ ) which is an improvement over the basic model run. However, even this model run does not reproduce the convective mass fluxes above $200 \mathrm{hPa}$ as archived in the ERA-Interim reanalyses.

Figure 6 also includes results from run "O_EIar" in which TOMCAT was modified to read in the archived convective mass fluxes. In this run, as expected, the model convection agrees with the ERA-Interim reanalyses. The small difference between panels (a) and (i) are due to the lower resolution of the model run compared to the archived data.

Finally, Fig. 6 includes results from runs "P_det", "A_E40" and "K_L31" which used the same operational analyses for 2005. Here runs "P_det" and "K_L31" have the same vertical resolution (L31) while run "A_E40" has a higher vertical resolution (L60). Increasing the vertical resolution in run "A_E40" does not have a significant impact on convection. However, the increase in vertical resolution on going from ECMWF L31 to L60 is mainly in the stratosphere and so would not be expected to impact greatly on convection.

Figure 7 summarises the comparison of the tropical annual mean (2005) convective mass fluxes from ERA-Interim and a range of TOMCAT runs. Panel (a) compares different versions of the model and forcing wind fields, panel (b) compares different model and wind resolutions and panel (c) compares the impact of different surface evaporation fluxes. Figure $7 \mathrm{a}$ shows that up to about $300 \mathrm{hPa}$ the experiments with different model formulation are similar to the archived
ECMWF values. Interestingly, run "N_1991", which used older ECMWF operational analyses from 1990/91, shows the largest modelled convective mass fluxes below $200 \mathrm{hPa}$ in this panel. Above $300 \mathrm{hPa}$ there is a sharp fall off in the modelled convection except for runs "N_1991", "P_det" and run "O_EIar" which uses archived mass fluxes. The sharp fall in the modelled convection from runs "N_1991" and "P_det" occurs at/above $200 \mathrm{hPa}$. Run "P_det", in which a lower entrainment rate is used, has significant convective mass fluxes extending higher (i.e. $0.001 \mathrm{~kg} \mathrm{~m}^{-2} \mathrm{~s}^{-1}$ reaches $200 \mathrm{hPa}$ ) than the other runs which diagnose convection. However, this profile comparison confirms that run "P_det" also fails to reproduce the archived convective mass fluxes between 200 and $100 \mathrm{hPa}$. Figure $7 \mathrm{~b}$ confirms that changing the resolution of the model and the analyses used to force the model has little impact on the diagnosed convection in TOMCAT. Higher resolution does lead to slightly more convection but the difference is not large. Note that the model version which used archived mass fluxes (i.e. as used in run "O_EIar") would show even less sensitivity to resolution. Figure $7 \mathrm{c}$ shows that large changes to the assumed surface evaporation fluxes do have a large impact on modelled convection in the lower and mid troposphere.

\subsection{Cloud top height comparison}

A critical property of a convective parameterisation is the ability to accurately diagnose from the grid-scale forcing the depth to which convection occurs (e.g., Mahowald et al., 1995). As the formation of convective clouds depends on the occurrence of cumulus updrafts, observed cloud top height in convective regions can be used as a measure of the depth of convection. 
(a) MODIS

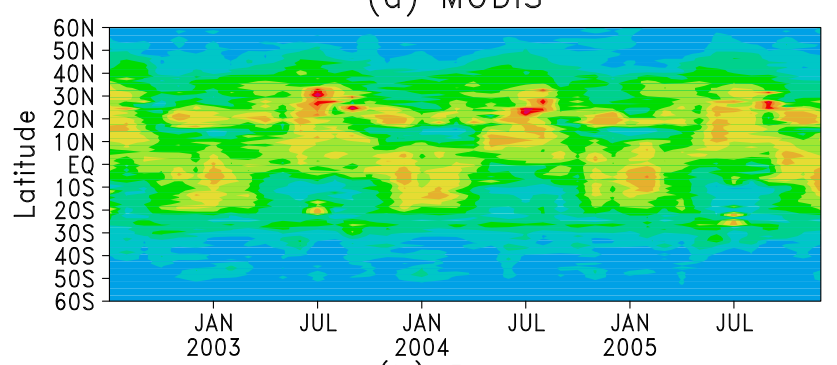

(b) Run $A$
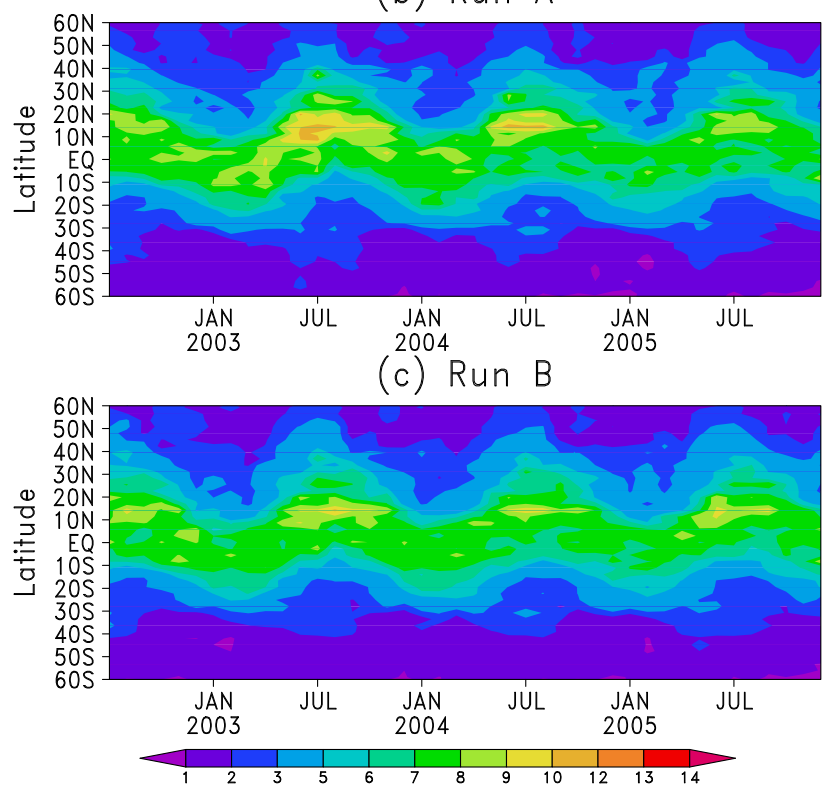

Fig. 8. Time series of monthly mean cloud top height (km) from (a) MODIS (b) run "A_E40", and (c) run "B_EI".

Figure 8 compares the observed cloud top height from MODIS for 2002-2005 with TOMCAT runs "A_E40" and "B_EI". These model runs are representative of the basic TOMCAT runs which diagnose convection. The observations show all observed clouds while the model results only show convective clouds. The model runs "A_E40" and "B_EI" capture the observed annual cycle of tropical (convective) clouds with the strongest convection occurring in the summer hemisphere. The modelled average tropical cloud top height peaks at about $10 \mathrm{~km}$ in the northern summer and about $8 \mathrm{~km}$ in the southern summer. This underestimates the observations which show mean cloud top heights up to $12-$ $13 \mathrm{~km}$ in both summer hemispheres.

Figure 9 shows a further comparison between MODIS and runs "A_E40", "B_EI", "K_L31" and "P_det". For this figure, the maximum daily cloud top height in the tropics $\left(30^{\circ} \mathrm{S}-\right.$ $30^{\circ} \mathrm{N}$ ) was found and then averaged into a monthly value. The highest monthly mean maximum cloud top heights occur in the northern summer and are up to $15 \mathrm{~km}$. In general TOMCAT underestimates the observed average maximum cloud top height and in particular these large values

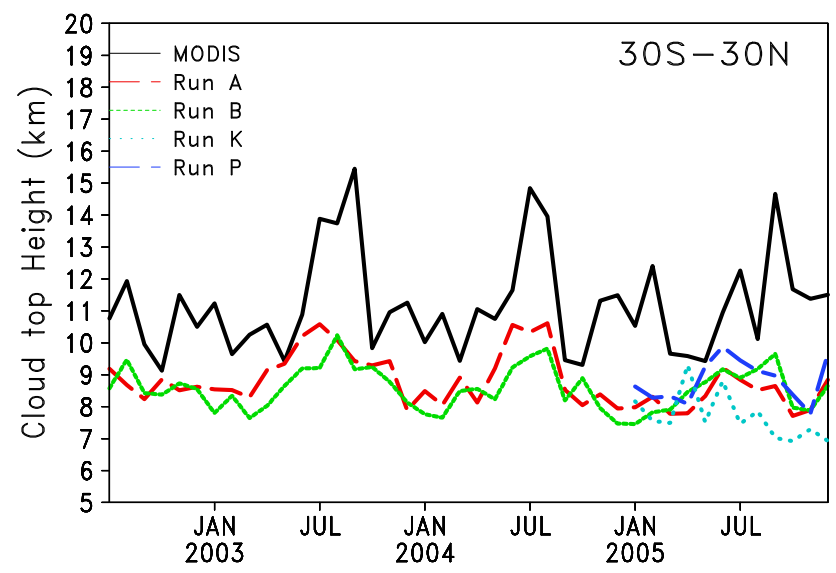

Fig. 9. Time series of monthly mean maximum daily cloud top height $(\mathrm{km})$ for 2002-2005 averaged between $30^{\circ} \mathrm{S}-30^{\circ} \mathrm{N}$ from MODIS and model runs "A_E40", "B_EI", "K_L31" and "P_det".

around July. Run "KLL31", which has a lower vertical resolution than run "A_E40", generally shows a lower cloud top height. For this version of the model, modifications to the entrainment/detrainment rates in run "P_det" increase the cloud top height by up to $2 \mathrm{~km}$. However, the model still underestimates the highest observed cloud top heights.

Overall, Figs. 8 and 9 confirm that the model underestimates the vertical extent of tropical convection but the discrepancy of a few $\mathrm{km}$ in mean cloud top height does not appear as large as the differences in the profile of the convective mass fluxes.

\subsection{Convective precipitation}

Surface rain rate is an important parameter in meteorology and is also important for the washout of some chemically active species. As precipitation rates are measured and archived by NWP reanalyses, they provide another meteorological comparison to test the overall performance of the CTM convection schemes. Column integrated precipitation will not be sensitive to key issues such as extent of convection in the tropical UT, but nevertheless will provide some information on the overall fidelity of the schemes used. Moreover, the wet deposition is also a key process for some trace gases and aerosols in the troposphere. Therefore, a discussion of convective precipitation will provide some useful information especially for the CTM modellers who are using the different ECMWF analyses.

Figure 10 shows zonal mean precipitation rates from observations (GPI and CMAP), meteorological reanalyses (ERA-40 and ERA-Interim) and model runs "A_E40" and "B_EI" from 1989 to 2005. The much larger precipitation rates in ERA-40 compared to ERA-Interim and the observations can clearly be seen. The model captures the seasonal variation in precipitation. In the tropics, run "A_E40", forced by ERA-40 reanalyses, produces stronger precipitation than 

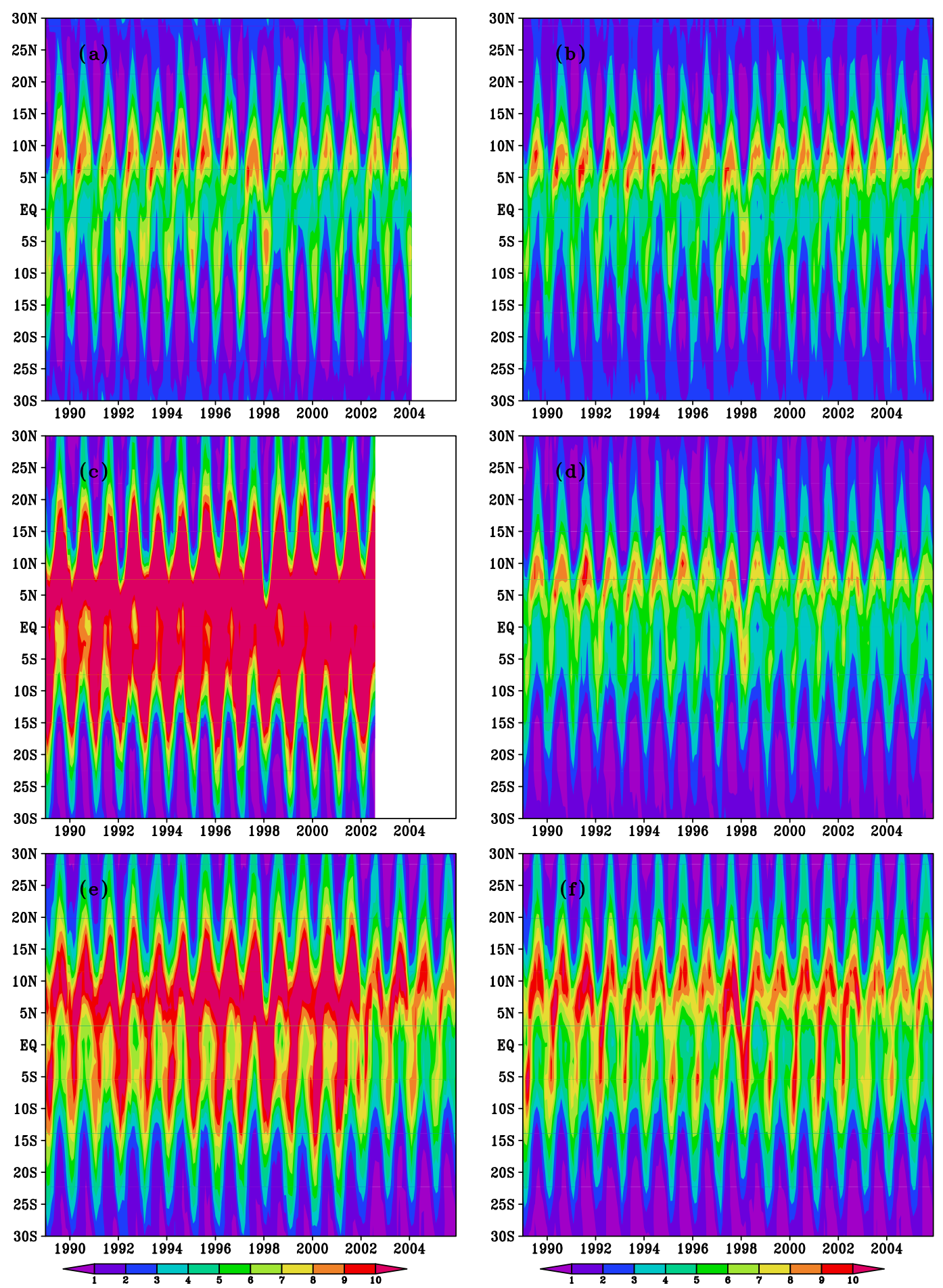

Fig. 10. Zonal mean convective precipitation (mm/day) from (a) GPI data, (b) CMAP data, (c) ERA-40 reanalyses, (d) ERA-Interim reanalyses, (e) run "A_E40", and (f) run "B_EI".

run "B_EI" which was forced by ERA-Interim, but both runs significantly underestimate precipitation in the extra-tropics. However, run "B_EI" overestimates the peak mean values in the tropics compared to the observations and ERA-Interim, while run "A_E40" still underestimates the very large values of ERA-40. Further comparisons of precipitation rates for January and and July 2005 are shown in Fig. 11. This shows that the model generally captures the latitudinal variation of 

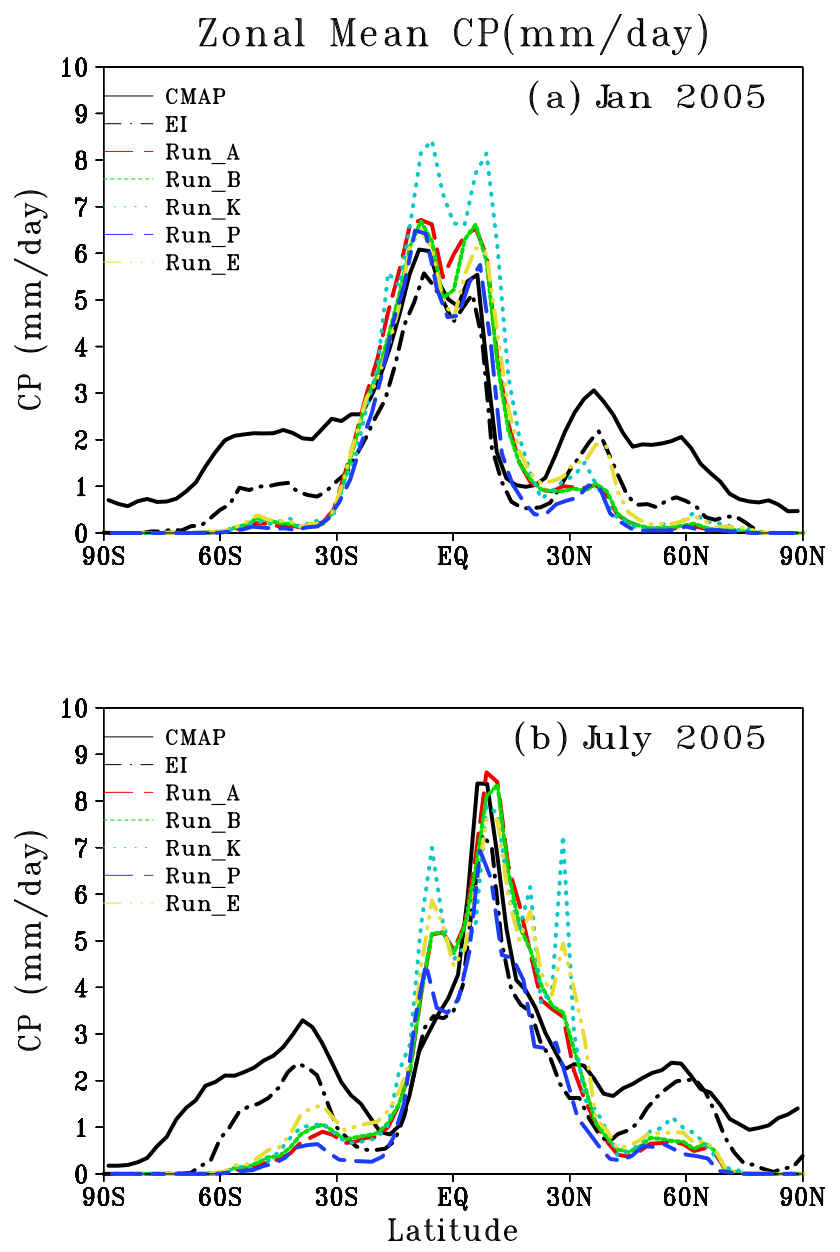

Fig. 11. Zonal mean convective precipitation ( $\mathrm{mm} /$ day) from CMAP data, ERA-Interim reanalyses and model runs "A_E40", "B_EI", "K_L31", "P_det" and "E_EInewevap" for (a) January 2005, and (b) July 2005.

the observed/ERA-Interim precipitation but there are large differences between the experiments. Runs "A_E40" and "B_EI" slightly overestimate the observations in the tropics. Runs "KLL31" and "P_det" both use a lower vertical resolution. Run "KLL31" overestimates the observed precipitation rates in the tropics while run "P_det", which uses ISCCP data to specify the fraction of saturated water in each grid box, gives much better agreement. The model still underestimates the precipitation at latitudes higher than $30^{\circ}$, though there is some improvement near $35^{\circ}-40^{\circ}$ using the updated Tiedkte convection scheme (Run "F_EInewconv").

\subsection{Radon tracers}

In this section we use observations of radon to investigate the accuracy of different convective treatments in the CTM. A number of the model runs include radon as a tracer using a typical source distribution. Figure 12 compares how modelled radon from selected runs compares with observations at a range of surface sites. Generally, the model reproduces the observed magnitude of radon, showing that the assumed radon emissions produce realistic surface distributions. TOMCAT gives a much better simulation of ${ }^{222} \mathrm{Rn}$ for the oceanic sites (e.g., Amsterdam Island and Bermuda) since these sites are mainly affected by large-scale transport (see Zhang et al., 2008). However, the largest discrepancy occurs at the continental European station of Hohenpeissenberg where the model overestimates the surface observations by up to a factor of 2. Zhang et al. (2008) pointed out that this is a challenging site for GCMs to simulate because of the orography. This is also the case for CTMs like TOMCAT. There are various possible reasons for this overestimation. Zhang et al. (2008) mentioned two main reasons from their GCM simulations: (1) The observed surface ${ }^{222} \mathrm{Rn}$ depends strongly on the boundary layer. (2) The horizontal resolution in their GCM was coarse $(\sim 300 \mathrm{~km})$ which is similar to the experiments "A_E40" and "B_EI". Another possible reason is that the ${ }^{222} \mathrm{Rn}$ flux we used in the model from Jacob et al. (1997) may overestimate the local emissions. For example, Conen and Robertson (2002) reported that the direct of ${ }^{222} \mathrm{Rn}$ flux measurement at this site is 0.75 0.88 atoms $\mathrm{cm}^{-2} \mathrm{~s}^{-1}$, while Zegvary et al. (2009) also reported even lower radon flux in Europe.

There are limited ${ }^{222} \mathrm{Rn}$ vertical profiles from measurements. The climatological mid-latitude ${ }^{222} \mathrm{Rn}$ vertical profiles from Liu et al. (1984) have been widely used for the evaluation of the tracer transport in global models (e.g., Stevenson et al., 1998; Zhang et al., 2008). The winter/summer ${ }^{222} \mathrm{Rn}$ observations were obtained from individual aircraft measurements at different continental locations from 1952 to 1972 (i.e., seven profiles for the winter and twenty three profiles for the summer). Figure 13a and b compare observed and modelled mean profiles of radon over Northern Hemisphere land areas for summer (JJA) and winter (DJF). Here we averaged the modelled ${ }^{222} \mathrm{Rn}$ output between $30^{\circ}-60^{\circ} \mathrm{N}$ among the land regions based on the land-sea mask information since there is limited information about the exact location and local time in the observation profiles. The observations show stronger lifting of radon (i.e. large concentrations around $10 \mathrm{~km}$ ) in the summer compared to the winter. The model runs which include convection agree reasonably well with the summer observations. Runs "C_E40noconv" and "D_EInoconv", which do not include convection more clearly underestimate the observations, as expected. The stronger convective transport to higher altitudes in run "O_EIar" appears to cause the model overestimation at the highest level $(11 \mathrm{~km})$. However, the data does not extend to higher altitudes where the model-model differences are more prominent. In winter all the model runs show weaker convection and agree with the profile shape above $5 \mathrm{~km}$, though none of the runs captures the observed C-shape profile at this latitude. Figure 13c and $\mathrm{d}$ show the absolute differences of radon between runs 

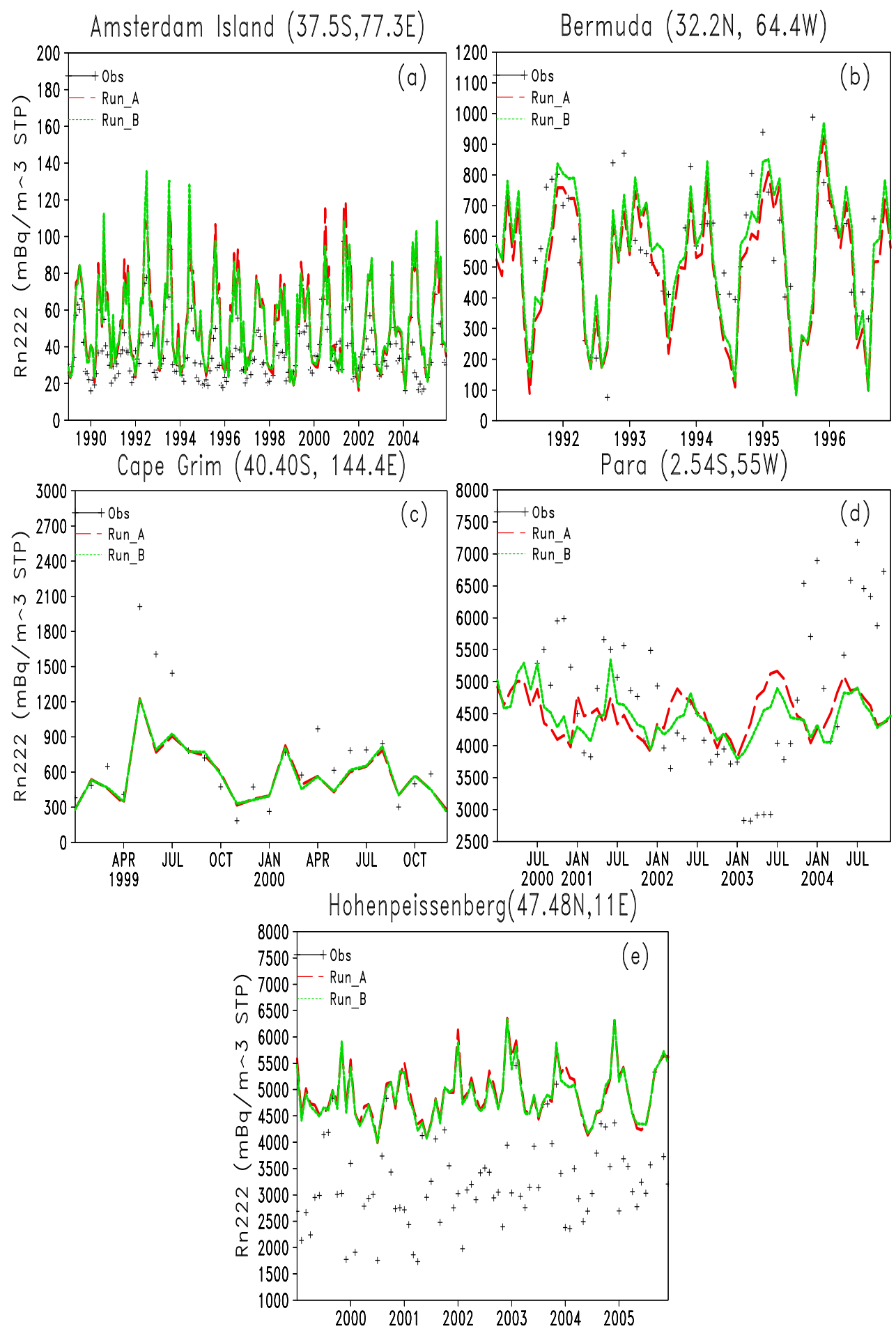

Fig. 12. Comparison of observed surface radon concentrations $\left(\mathrm{mBq} / \mathrm{m}^{3} \mathrm{STP}\right)$ with model runs "A_E40" and "B_EI" at (a) Amsterdam Island $\left(37.5^{\circ} \mathrm{S}, 77.3^{\circ} \mathrm{E}\right)$, (b) Bermuda $\left(32.2^{\circ} \mathrm{N}, 295.6^{\circ} \mathrm{E}\right)$. (c) Cape Grim $\left(40.4^{\circ} \mathrm{S}, 144.4^{\circ} \mathrm{E}\right)$, (d) Parà, Brazil $\left(2.5^{\circ} \mathrm{S}, 305^{\circ} \mathrm{E}\right)$, and (e) Hohenpeissenberg $\left(47.5^{\circ} \mathrm{N}, 11^{\circ} \mathrm{E}\right)$. Note different $\mathrm{x}$-axis and $\mathrm{y}$-axis scales.

"A_E40"-"B_EI", "D_EInoconv"-"B_EI”, “C_E40noconv""A_E40", and "F_EInewconv"-"E_EInewevap" for summer and winter, respectively. The model forced by ERA-40 gives slightly larger modelled radon tracer in the middle and upper troposphere than when forced by ECMWF-Interim reanalyses. The difference between runs "C_E40noconv" and 

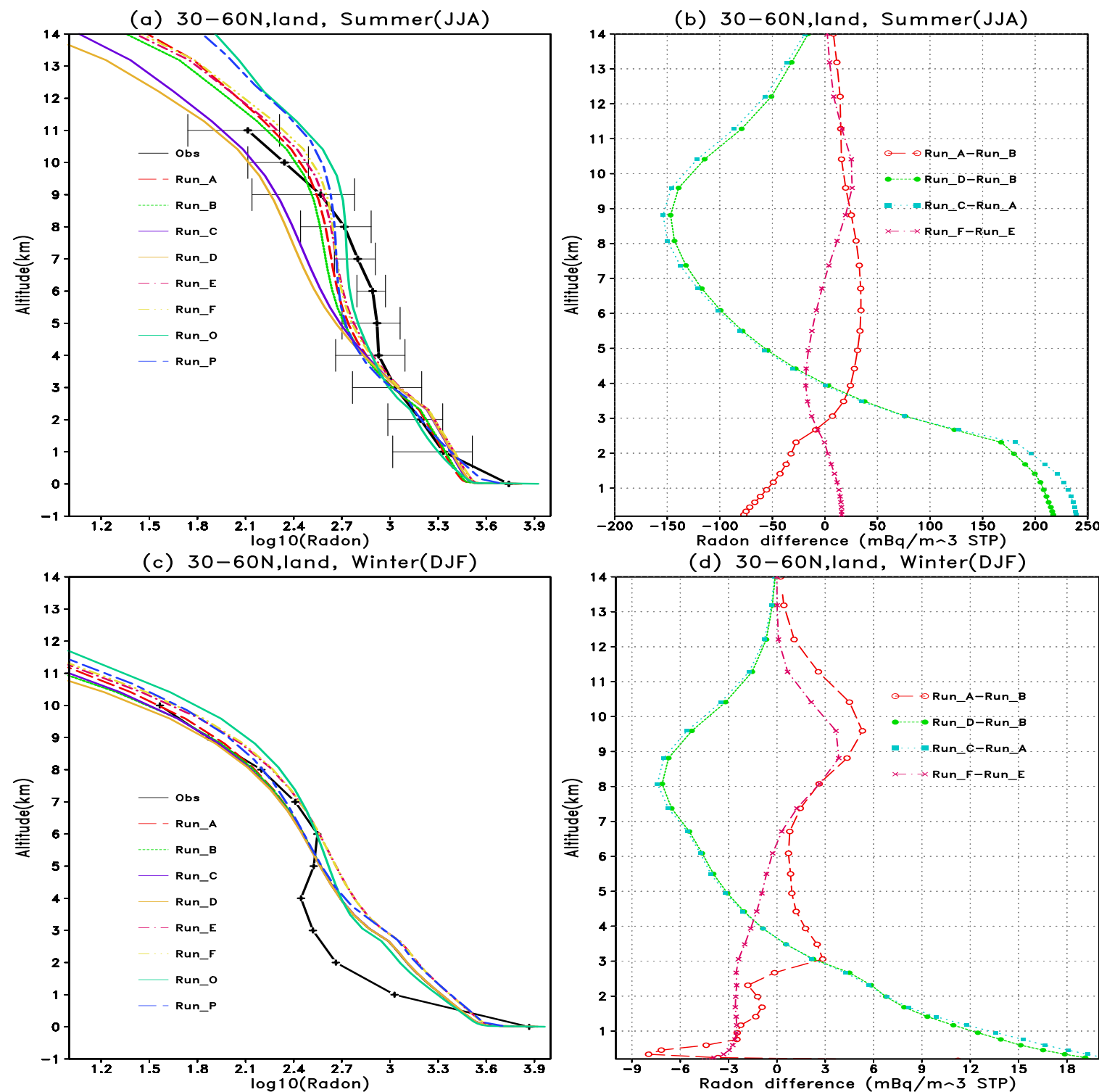

Fig. 13. Comparison of observed radon profiles (mBq/m $\mathrm{m}^{3} \mathrm{STP}$ ) averaged between $30^{\circ} \mathrm{N}$ and $60^{\circ} \mathrm{N}$ over land for (a) summer (JJA) and (b) winter (DJF) with model runs "A_E40", "B_EI", "C_E40noconv", "D_EInoconv", "E_EInewevap", "F_EInewconv", "O_EIar" and "P_det". Panels (c) and (d) show the differences between runs "A_E40"-"B_EI", "D_EInoconv"-“B_EI", "C_E40noconv"-“A_E40", and "F_EInewconv"-"E_EInewevap" for summer and winter, respectively.

"A_E40", runs "D_EInoconv" and "B_EI"emphasise the effect of convection in the modelled tracers in summer and winter. Obviously, the convection is very significant in summer but small in winter for the northern hemisphere midlatitudes as expected.

Figure 14 is a further comparison of radon profiles with campaign data from Moffett Field in June 1994 (Kritz et al., 1998) and the North Atlantic Regional Experiment (NARE) in August 1993 (Zaucker et al., 1996). The Moffett Field observations show large day-to-day variability in the profiles during the campaign. The observations from NARE do not extend above $6 \mathrm{~km}$ but show the modelled radon mixing ra- tios in the lower atmosphere are reasonable. As model run "O_EIar" does not cover the year of the observations results from runs "A_E40" and "B_EI" are plotted for both the observation period and for 2005 to show the impact of interannual variability. Run "O_EIar" produces higher radon values in the mid and upper troposphere than the other 2005 runs, although the model output for 1994 from runs "A_E40" and "B_EI" are larger above $11 \mathrm{~km}$.

There have been extensive studies of the impact of resolution on the fidelity of model simulations (e.g., Phillips et al., 1995; Brankovic and Gregory, 2001; Lorant and Royer, 2001; Pope and Stratton, 2002; Rind et al., 2007; Wild, 2007; 

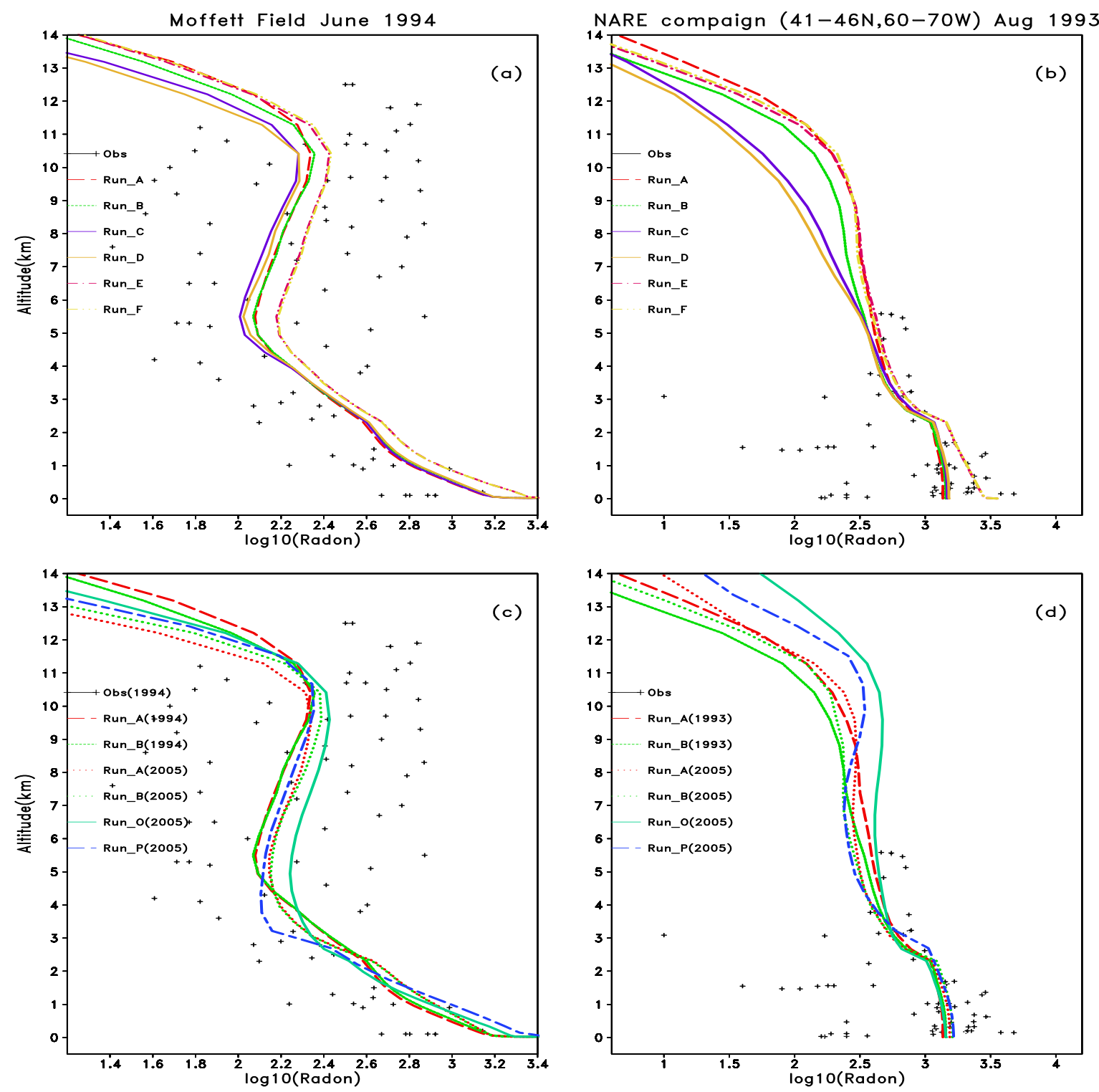

Fig. 14. Comparison of observed radon profiles ( $\left.\mathrm{mBq} \mathrm{m}^{-3} \mathrm{STP}\right)$ at (a) Moffett Field in June 1994 and (b) NARE campaign in August 1993 with results from model runs "A_E40", "B_EI", "C_E40noconv", "D_EInoconv", "E_EInewevap", "F_EInewconv" and "O_EIar". Panels (c) and (d) show the same two campaigns as (a) and (b), respectively, along with model runs "A_E40" and "B_EI" but also include results from model runs "A_E40", "B_EI", "O_EIar" and "P_det" sampled for 2005.

Patra et al., 2008). They have shown that model resolution can play an important role in the simulation quality.

Clearly, the model has stronger vertical tracer transport at higher horizontal resolution. We have already shown that the diagnosed convection between these runs does not vary greatly, though it is stronger at higher resolution, and the large-scale winds are the same. An additional factor which leads to larger transport of radon at higher resolution is the ability of the model to resolve stronger spatial gradients in the tracer fields, and maintain larger local values. It should be noted that the vertical transport is not the only factor that affects the radon profile. Horizontal mixing, particularly near coastal or snow covered areas may play a role, as there are strong spatial gradients in radon emissions here.

\section{Discussion}

The results presented here show a wide range in performance of the convection scheme in different CTM simulations. In particular, the comparison of the convective mass fluxes between the runs which diagnose convection and that which 
reads in the archived values will explain a large part of the CTM differences seen in Hoyle et al. (2010). The use of convective mass fluxes from the same NWP system which produced the large-scale analyses appears to be more selfconsistent than diagnosing them within the CTM with a different code. However, this does not necessarily mean that the archived convective mass fluxes will directly lead to more realistic modelled tracer distributions.

In a recent study, Hossaini et al. (2010) used the TOMCAT/SLIMCAT CTM to investigate the transport of the short-lived species $\mathrm{CHBr}_{3}$ (lifetime about 30 days) and $\mathrm{CH}_{2} \mathrm{Br}_{2}$ (lifetime about 6 months) to and through the TTL. The version of TOMCAT used was the same as run "A_E40" in this study, i.e. the default model but with 2007 winds. When comparing with aircraft campaign data, Hossaini et al. (2010) showed that the p-level TOMCAT model tended to overestimate the abundance of these species in the TTL, suggesting that modelled vertical transport may be too rapid. In this study we show that run "A_E40" produces convection which is less intense than other simulations, notably runs "O_EIar" and "P_det". The implication here, therefore, is that stronger convection in TOMCAT would degrade the comparison of these short-lived tracers in the upper troposphere. Hossaini et al. (2010) argued that the $\theta$-level model (SLIMCAT) gave a more realistic tracer profile in the TTL due to slower large-scale advection. It is possible that a too strong large-scale advective transport overcompensated for an underestimate in convection.

Hossaini et al. (2010) also looked at the effect of convection on $\mathrm{CHBr}_{3}$ and $\mathrm{CH}_{2} \mathrm{Br}_{2}$ by performing runs with this process switched off. For these species, even without modelled convection (though still with mixing out of the PBL), there was still significant transport to the TTL. Of course, the effect would have been more marked in a version of TOMCAT with stronger convection (e.g. model version used in runs "O_EIar" or "P_det" as opposed to "A_E40") and for tracers with even shorter lifetimes. Lawrence and Salzmann (2008) raised questions about how results from experiments such as this should be interpreted. They argued that the effects of convection cannot be removed by simply turning off the parameterisation in a CTM. They suggest that there is large overlap between the convective and large-scale transport, i.e. the resolved winds used in the CTM dynamics already contain information about the convection.

\section{Conclusions}

We have used the TOMCAT 3-D off-line chemical transport model to investigate issues related to the treatment of convective tracer transport. The basic model diagnoses convection from the specified large-scale meteorological fields using a version of the Tiedtke scheme. For this work the Tiedtke scheme in the model has been updated to include midlevel convection along with a new option to specify convec- tion from archived convective mass fluxes. These archived mass fluxes provide a reference for the convection calculated within the CTM.

In general the model versions which diagnose convection underestimate the convective mass fluxes compared to the ECMWF archived values. The inclusion of midlevel convection in the updated TOMCAT model improves comparisons at mid-high latitudes in the mid troposphere but there is still a significant disagreement in the latitudinal distribution (i.e., the modelled mass fluxes and precipitation are too low at mid-high latitudes). However, the most significant disagreement concerns the vertical extent of convection. The archived mass fluxes show significant tracer transport to about $100 \mathrm{hPa}$ in the tropics while the diagnosed fluxes extend to only around $200 \mathrm{hPa}$.

A range of model experiments have been performed with the version of the model which diagnoses convection. With the identical model code, there can be relatively large differences in diagnosed convection with different versions of ECMWF datasets. This needs to be borne in mind when comparing CTM results from different studies or when using earlier evaluation of CTM convection to interpret recent results. The resolution of the CTM did not make a great difference to the extent of diagnosed convective mass fluxes. The archived mass fluxes show strong convection transport up to $100 \mathrm{hPa}$, but none of the model experiments using the convection scheme are able to capture this though the model run using the old operational analyses has higher convective updraft mass fluxes. GCMs using different cumulus convection schemes are also not able to reproduce this well (e.g., Tost et al., 2010). This is a challenge for CTMs/GCMs. At higher resolution there was more convective tracer transport. Changes to parameters in the Tiedtke scheme (entrainment/detrainment rates) could be used to increase the extent of convective transport, but that may affect the precipitation diurnal cycle as well as the mean and variability of the simulated precipitation as mentioned by Bechtold et al. (2004). Moreover, it is not clear if the changes in the entrainment/detrainment rates would be altered by changes in the PBL parameterisation, the closure assumptions in the cumulus parameterisation and other model physical processes (Wang et al., 2007). Changes to the modelled surface evaporation fluxes only impact shallow convective mass fluxes in TOMCAT.

The radon tracer has been included in the model runs. The limited profile observations available do not really discriminate between the different model versions. Clearly, some treatment of model convection in this paper improves agreement with observations. Despite relatively small changes in convective mass fluxes with resolution, higher model resolution did result in high radon mixing ratios being transported to the mid troposphere. However, variability in the observations means that both the diagnosed convection and using the archived convection agree with the data which extends up to $10 \mathrm{~km}$ in middle latitudes. 
While the use of archived mass fluxes would appear to be an improvement for the CTM, and provide a model which is consistent with the forcing ECMWF meteorology, the significant transport to the tropical UT produced in this model needs to be tested. Observations of short-lived species in the tropical UT will be used for this in a future study extending on the work of Hossaini et al. (2010) and Aschmann et al. (2009).

Acknowledgements. This work was supported by the European Union SCOUT-O3 project and by NERC (NCEO and NCAS). The ECMWF analyses were obtained via the British Atmospheric Data Centre. We would like to thank three reviewers for their time and valuable suggestions which improved the quality of this paper.

Edited by: P. Haynes

\section{References}

Arakawa, A.: Closure assumptions in the cumulus parameterization problem, in: The Representation of Cumulus Convection in Numerical Models, edited by: Emanuel, K. A. and Raymo nd, D. J., Amer. Meteor. Soc., Boston, USA, 1-15, 1993.

Arkin, P. A. and Meisner, B. N.: The relationship between largescale convective rainfall and cold cloud over the Western Hemisphere during 1982-1984, Mon. Weather Rev., 115, 51-74, 1987.

Aschmann, J., Sinnhuber, B.-M., Atlas, E. L., and Schauffler, S. M.: Modeling the transport of very short-lived substances into the tropical upper troposphere and lower stratosphere, Atmos. Chem. Phys., 9, 9237-9247, doi:10.5194/acp-9-9237-2009, 2009.

Barret, B., Williams, J. E., Bouarar, I., Yang, X., Josse, B., Law, K., Pham, M., Le Flochmoën, E., Liousse, C., Peuch, V. H., Carver, G. D., Pyle, J. A., Sauvage, B., van Velthoven, P., Schlager, H., Mari, C., and Cammas, J.-P.: Impact of West African Monsoon convective transport and lightning $\mathrm{NO}_{\mathrm{x}}$ production upon the upper tropospheric composition: a multi-model study, Atmos. Chem. Phys., 10, 5719-5738, doi:10.5194/acp-105719-2010, 2010.

Bechtold, P., Bazile, E., Guichard, F., Mascart, P., and Richard, E.: A mass-flux convection scheme for regional and global model, Q. J. Roy. Meteor. Soc., 127, 869-886, 2001.

Bechtold, P., Chaboureau, J. P., Beljaars, A., Betts, A. K., Köhler, M., Miller, M., and Redelsperger, J. L.: The simulation of the diurnal cycle of convective precipitation over land in a global model, Q. J. Roy. Meteor. Soc., 130, 3119-3137, 2004.

Berntsen, T., Fuglestvedt, J., Myhre, G., Stordal, F., and Berglen, T.: Abatment of greenhouse gases: does location matter?, Climatic Change, 74, 377-411, doi:10.1007/s10584-006-0433-4, 2006.

Brankovic, T. and Gregory, D.: Impact of horizontal resolution on seasonal integrations, Clim. Dynam., 18, 123-143, 2001.

Breider, T., Chipperfield, M. P., Richards, N. A. D., Carslaw, K. S., Mann, G. W., and Spracklen, D. V.: The impact of BrO on dimethylsulfide in the remote marine boundary layer, Geophys. Res. Lett., 37, L02807, doi:10.1029/2009GL040868, 2010.

Chipperfield, M.: New version of the TOMCAT/SLIMCAT offline chemical transport model: intercomparison of stratospheric tracer experiments, Q. J. Roy. Meteor. Soc., 132, 1179-1203, doi:10.1256/qj.05.51, 2006.
Chipperfield, M. P.: Multiannual simulations with a threedimensional chemical transport model, J. Geophys. Res., 104, 1781-1805, 1999.

Chipperfield, M. P., Cariolle, D., Simon, P., Ramaroson, R., and Lary, D. J.: A 3-dimensional modeling study of trace species in the Arctic lower stratosphere during winter 1989-1990, J. Geophys. Res., 98, 7199-7218, 1993.

Conen, F. and Robertson, L. B.: Latitudinal distribution of radon222 flux from continents, Tellus B, 54, 127-133, 2002.

Emanuel, K. A.: Atmospheric Convection, Oxford Univ. Press, New York, 580 pp., 1994.

Hodzic, A., Vautard, R., Chepfer, H., Goloub, P., Menut, L., Chazette, P., Deuzé, J. L., Apituley, A., and Couvert, P.: Evolution of aerosol optical thickness over Europe during the August 2003 heat wave as seen from CHIMERE model simulations and POLDER data, Atmos. Chem. Phys., 6, 1853-1864, doi:10.5194/acp-6-1853-2006, 2006.

Holtslag, A. A. M. and Boville, B.: Local versus nonlocal boundary layer diffusion in a global climate model, J. Climate, 6, 1825$1842,1993$.

Hossaini, R., Chipperfield, M. P., Monge-Sanz, B. M., Richards, N. A. D., Atlas, E., and Blake, D. R.: Bromoform and dibromomethane in the tropics: a 3-D model study of chemistry and transport, Atmos. Chem. Phys., 10, 719-735, doi:10.5194/acp-10-719-2010, 2010.

Hoyle, C. R., Marécal, V., Russo, M. R., Arteta, J., Chemel, C., Chipperfield, M. P., D’Amato, F., Dessens, O., Feng, W., Harris, N. R. P., Hosking, J. S., Morgenstern, O., Peter, T., Pyle, J. A., Reddmann, T., Richards, N. A. D., Telford, P. J., Tian, W., Viciani, S., Wild, O., Yang, X., and Zeng, G.: Tropical deep convection and its impact on composition in global and mesoscale models - Part 2: Tracer transport, Atmos. Chem. Phys. Discuss., 10, 20355-20404, doi:10.5194/acpd-10-20355-2010, 2010.

Jacob, D. J. and Prather, M. J.: Radon-222 as a test of convective transport in a general circulation model, Tellus B, 42, 118-134, 1990.

Jacob, D. J., Prather, M. J., Rasch, P. J., et al.: Evaluation and intercomparison of global atmospheric transport models using ${ }^{222} \mathrm{Rn}$ and other short-lived tracers, J. Geophys. Res., 102, 5953-5970, 1997.

Josse, B., Simon, P., and Peuch, V. H.: Radon global simulations with the multiscale chemistry and transport model MOCAGE, Tellus B, 56, 339-356, 2004.

Kain, J. S., Baldwin, M. E., and Weiss, S. J.: Parameterized updraft mass flux as a predictor of convective intensity, Weather Forecast., 106, 106-116, 2002.

Kritz, M. A., Rosner, S. W., and Stockwell, D. Z.: Validation of an offline three-dimensional chemical transport model using observed radon profiles -1 . Observations, J. Geophys. Res., 103, 8425-8432, 1998.

Lawrence, M. G. and Salzmann, M.: On interpreting studies of tracer transport by deep cumulus convection and its effects on atmospheric chemistry, Atmos. Chem. Phys., 8, 6037-6050, doi:10.5194/acp-8-6037-2008, 2008.

Liu, S. C., McAfee, J. R., and Cicerone, R. J., Radon 222 and tropospheric vertical transport, J. Geophys. Res., 89, 7219-7292, doi:10.1029/JD089iD05p07291, 1984.

Lorant, V., and Royer, J. F., Sensitivity of equatorial convection to horizontal resolution in aquaplanet simulations with a variable- 
resolution GCM, Mon. Weather Rev., 129, 2730-2745, 2001.

Mahowald, N. M., Rasch, P. J., and Prinn, R. G.: Cumulus parameterizations in chemical transport models, J. Geophys. Res., 100, 26173-26189, 1995.

Mahowald, N. M., Rasch, P. J., Eaton, B. E., Whittlestone, S., and Prinn, R. G.: Transport of ${ }^{222}$ radon to the remote troposphere using the model of atmospheric transport and chemistry and assimilated winds from ECMWF and the National Center for Environmental Prediction/NCAR, J. Geophys. Res., 102, 28139-28151, 1997.

Manabe, S., Smagorinsky, J., and Strickler, R. F.: Simulated climatology of a general circulation model with a hydrologic cycle, Mon. Weather Rev., 93, 769-798, 1965.

Menzel, W. P., Frey, R. A., Zhang, H., Wylie, D. P., Moeller, C. C., Holz, R. E., Maddux, B., Baum, B. A., Strabala, K. I., and Gumley, L. E.: MODIS global cloud-top pressure and amount estimation: algorithm description and results, J. Appl. Meteorol. Clim., 47, 26173-26189, doi:10.1175/2007JAMC1705.1, 2008.

Morrissey, M. L. and Greene, J. S.: Comparison of two satellitebased rainfall algorithms using Pacific atoll raingage data, J. Appl. Meteorol., 32, 411-425, 1993.

Patra, P. K., Law, R. M., Peters, W., et al., TransCom model simulations of hourly atmospheric $\mathrm{CO}_{2}$ : Analysis of synoptic-scale variations for the period 2002-2003, Global Biogeochem. Cy., 22, GB4013, doi:10.1029/2007GB003081, 2008.

Phillips, J. T., Corsetti, L. C., Grotch, S. L., The impact of horizontal resolution on moist processes in the ECMWF model, Clim. Dynam., 11, 85-102, 1995.

Pope, V. D. and Stratton, R. A., The processes governing horizontal resolution sensitivity in a climate model, Clim. Dynam., 19, 211236, 2002.

Prather, M. J.: Numerical advection by conservation of secondorder moments, J. Geophys. Res., 91, 6671-6681, 1986.

Rind, D., Lerner, J., Jonas, J., and McLinden, C., Effects of resolution and model physics on tracer transports in the NASA Goddard Institute for Space Studies general circulation models, J. Geophys. Res., 112, doi:10.1029/2006JD007476, 2007.

Rossow, W. B., Walker, A. W., Bueschel, D. E., and Roiter, M. D.: International Satellite Cloud Climatology Project (ISCCP) Documentation of New Cloud Datasets, WMO/TD-No 737, World Meteorological Organization, 115 pp., 1996.

Russo, M. R., Marécal, V., Hoyle, C. R., Arteta, J., Chemel, C., Chipperfield, M. P., Dessens, O., Feng, W., Hosking, J. S., Telford, P. J., Wild, O., Yang, X., and Pyle, J. A.: Representation of tropical deep convection in atmospheric models, part 1: Meteorology and comparison with satellite observations, Atmos. Chem. Phys., 11, 2765-2786, doi:10.5194/acp-11-2765-2011, 2011.

Stevenson, D. S., Collins, W. J., Johnson, C. E., and Derwent, R. G.: Intercomparison and evaluation of atmospheric transport in a Lagrangian model (STOCHEM), and an Eulerian model (UM), using ${ }^{222} \mathrm{Rn}$ as a short-lived tracer, Q. J. Roy. Meteor. Soc., 124, 2477-2491, 1998.
Stockwell, D. Z. and Chipperfield, M. P.: A tropospheric chemical transport model: development and validatation of the model transport schemes, Q. J. Roy. Meteor. Soc., 125, 1743-1783, 1999.

Taguchi, S., Iida, T., and Moriizumi, J.: Evaluation of the atmospheric transport model NIRE-CTM-96 by using measured radon-222 concentrations, Tellus B, 54, 250-268, 2002.

Tiedtke, M. A.: A comprehensive mass flux scheme for cumulus parameterisation in large-scale model, Mon. Weather Rev., 117, 1779-1800, 1989.

Tost, H., Jöckel, P., and Lelieveld, J.: Influence of different convection parameterisations in a GCM, Atmos. Chem. Phys., 6, 54755493, doi:10.5194/acp-6-5475-2006, 2006.

Tost, H., Jöckel, P., and Lelieveld, J.: Lightning and convection parameterisations - uncertainties in global modelling, Atmos. Chem. Phys., 7, 4553-4568, doi:10.5194/acp-7-4553-2007, 2007.

Tost, H., Lawrence, M. G., Brühl, C., Jöckel, P., The GABRIEL Team, and The SCOUT-O3-DARWIN/ACTIVE Team: Uncertainties in atmospheric chemistry modelling due to convection parameterisations and subsequent scavenging, Atmos. Chem. Phys., 10, 1931-1951, doi:10.5194/acp-10-1931-2010, 2010.

Wang, Y., Zhou, L., and Hamilton, K.: Effect of convective entrainment/detrainment on the simulation of the tropical precipitation diurnal cycle, Mon. Weather Rev., 135, 567-585, 2007.

Wild, O.: Modelling the global tropospheric ozone budget: exploring the variability in current models, Atmos. Chem. Phys., 7, 2643-2660, doi:10.5194/acp-7-2643-2007, 2007.

Wild, O., Prather, M., Akimoto, H., Sundet, J., Isaksen, I., Crawford, J., Davis, D., Avery, M., Kondo, Y., Sachse, G., and Sandholm, S.: Chemical transport model ozone simulations for spring 2001 over the Western Pacific: regional ozone production and its global impacts, J. Geophys. Res., 109, doi:10.1029/2003JD004041, 2004.

Xie, P. and Arkin, P. A.: Global precipitation: a 17-year monthly analysis based on Gauge observations, satellite estimates, and numerical model outputs, B. Am. Meteorol. Soc., 78, 25392558, 1997.

Zaucker, F., Daum, P. H., Wetterauer, U., Berkowitz, C., Kromer, B., and Broecker, W. S.: Atmospheric ${ }^{222} \mathrm{Rn}$ measurements during the 1993 NARE Intensive, J. Geophys. Res., 101, 29149-29164, 1996.

Zegvary, T., Conen, F., and Ciais, P.: European ${ }^{222}$ Rn inventory for applied atmospheric studies, Atmos. Environ., 43, 1536-1539, 2009.

Zhang, K., Wan, H., Zhang, M., and Wang, B.: Evaluation of the atmospheric transport in a GCM using radon measurements: sensitivity to cumulus convection parameterization, Atmos. Chem. Phys., 8, 2811-2832, doi:10.5194/acp-8-2811-2008, 2008. 